\title{
Research on Cutting Performance in High-speed Milling of TC11 Titanium Alloy Using Self-propelled Rotary Milling Cutters
}

\section{Yujiang Lu}

Harbin University of Science and Technology

Tao Chen ( $\sim$ dotnetchen@163.com )

Harbin University of Science and Technology

\section{Research Article}

Keywords: TC11 titanium alloy, Self-propelled rotary cutter, Wear morphology, Wear mechanism, Surface quality

Posted Date: February 12th, 2021

DOI: https://doi.org/10.21203/rs.3.rs-205334/v1

License: (c) (i) This work is licensed under a Creative Commons Attribution 4.0 International License. Read Full License

Version of Record: A version of this preprint was published at The International Journal of Advanced Manufacturing Technology on July 6th, 2021. See the published version at https://doi.org/10.1007/s00170-021-07592-4. 


\title{
Research on Cutting Performance in High-speed Milling of TC11
}

\section{Titanium Alloy Using Self-propelled Rotary Milling Cutters}

\author{
Lu Yujiang, Chen Tao* \\ School of Mechanical and Power Engineering, Harbin University of Science and Technology, \\ Harbin 150080, China \\ (*Corresponding author: dotnetchen@163.com)
}

\begin{abstract}
Titanium alloy materials, with excellent chemical and physical properties, are widely applied to the manufacture of key components in the aerospace industry. Nevertheless, its hard-to-machine characteristic causes various problems in the machining process, such as severe tool wear, difficulty to ensure good surface quality, etc. To achieve high efficiency and quality of machining titanium alloy materials, this paper conducted an experimental research on the high-speed milling of TC11 titanium alloy with self-propelled rotary milling cutters. In the work, the wear mechanism of self-propelled rotary milling cutters was explored, the influence of milling velocity was analyzed on the cutting process, and the variation laws were obtained of milling forces, chip morphology and machined surface quality with the milling length. The results showed that in the early and middle stages of milling, the insert coating peeled off evenly under the joint action of abrasive and adhesive wear mechanisms. As the milling length increased, the dense notches occurred on the cutting edge of the cutter, the wear mechanism converted gradually into fatigue wear, and furthermore coating started peeling off the cutting edge with the occurrence of thermal fatigue cracks on the insert. As the milling length was further extended, the milling forces tended to intensify, the chip deformation worsened, and the obvious cracks occurred at the bottom of chips. Moreover, the rise in milling velocity reduced the tool wear resistance, increased obviously the milling forces and the surface roughness.
\end{abstract}

Keywords: TC11 titanium alloy, Self-propelled rotary cutter, Wear morphology, Wear mechanism, Surface quality

\section{Introduction}

With excellent physical and chemical properties, the titanium alloy is widely used in the aerospace, chemical and automobile industries [1-3]. However, such characteristics as poor thermal conductivity, strong chemical activity at high temperatures and low elastic modulus, cause widespread problems in machining, such as low machining efficiency, poor surface quality, and severe tool wear, etc. [4-6]. These problems restrict badly the application and promotion of titanium alloy materials. The PCD and PCBN, novel cemented carbide cutting tools, can improve the machining performance of titanium alloy, but its high cost and high demand for the machine tool rigidity limit the promotion of cemented carbide cutting tools. Therefore, it is necessary and urgent to explore a novel cutting tool with excellent cutting performance, low cost and suitability to machine titanium alloy materials. Moreover, it is of great theoretical and practical significance for solution to the difficulty in machining titanium alloy and improvement in machining quality to conduct researches on the cutting performance of the novel cutting tools. 
In the research on cutting the titanium alloy with conventional cutters, Sun et al. [7] carried out a single factor experiment on milling the titanium alloy with indexable coated carbide inserts, and obtained the curves of cutting forces and cutting power. Rashid et al. [8] investigated all possible tool wear mechanisms in the dry machining of the titanium alloy with uncoated carbide cutting tools, and found the mechanisms of adhesion, diffusion, attrition, and abrasion were associated with cratering of the rake surface. Koseki et al. [9] researched the coated cutting tool wear during the continuous turning of a titanium alloy, and suggested that the coating wear depended on the interfacial strength between adhesive material and coating as well as the strength of adhesive material at a high temperature. Daymi et al. [10] evaluated experimentally the influence of different milling conditions on the workpiece surface integrity, and concluded that the inclination angle of workpiece, an influential parameter for the surface roughness, provided the best surface finish at the angle $25^{\circ}$, and higher workpiece angle decreased slightly the compressive stress. Yang et al. [11] investigated the cutting performance of the new WC matrix composite tool material by the experiment on machining the titanium alloy, and found the high temperature and mechanical friction were the main causes for tool failure. Tan et al. [12] did experimentally a comparative research on the cutting performance of TiB2-based ceramic cutters and WC-Co composite cutters in the high-speed cutting of titanium alloy, and discovered that the superior cutting performance of the former to the latter was mainly attributed to its better oxidation resistance and high-temperature mechanical properties. Chowdhury et al. [13] investigated comparatively the wear performance of coated and uncoated carbide cutting tools in high-speed turning of TC4 titanium alloy, and the results showed that the tool coating improved significantly tool performance. Wang et al. [14,15] developed a special revolving cycloid milling cutter for machining the titanium alloy, and experimentally compared it with the ball end milling cutter in the cutting performance. The results revealed that the revolving cycloid milling cutter can significantly reduce the axial and tangential forces, and had better wear resistance and surface quality than the ball end milling cutter. These studies have provided some good ideas and solutions for the difficulties of machining the titanium alloy, but some problems still occur in the machining process, such as the concentration of tool wear, higher cutting temperature in the local area, etc.

The urgent need for improvement in the machining quality and the service life of cutting tools for machining the titanium alloy, promoted the advent of self-propelled rotary cutters with self-cooling characteristic. This has got much attention from many scholars. Lei et al. [16] developed a new driven rotary cutting tool for the high-speed machining of the titanium alloy, and conducted a comparative experiment on the driven rotary tool (DRT) and the stationary cutting tool. The experimental results showed that the DRT can significantly increase tool life. Olgun et al. [17] compared experimentally self-propelled rotary turning (SPRT) tools and actively driven rotary turning (ADRT) tools in terms of the cutting performance, and found that SPRT process yielded better tool life and machined part quality. Kishawy et al. [18-20] presented the models for predicting cutting forces, flank wear and chip flow to evaluate the cutting performance of self-propelled rotary tools in the machining process, and verified the correctness of predicted values by the experiments on machining the titanium alloy. Kossakowska et al. [21] explored the dependence of the rotational speed of self-propelled rotary tools (SPRT) on cutting parameters and revealed some important drawbacks and limitations of SPRT application. Dessoly et al. [22] 
developed and verified a thermal model for predicting the distribution of cutting temperatures, and compared self-propelled rotary tools ( SPRT ) and equivalent fixed tools during machining hardened steels in terms of cutting temperatures. The results showed that the SPRT generated lower cutting temperatures. Ezugwu et al. [23, 24] evaluated the tool wear in turning IMI 318 titanium alloy with self-propelled rotary tools (SPRT), and concluded that SPRT exhibited superior wear resistance and provided other major benefits, including the increase in tool life, lower cutting temperature and higher metal removal rate.

To sum up, the scholars have done a lot of relevant researches, mainly focusing on the cutting mechanisms and the experiments of conventional cutting tool, but some problems still remain unsolved well in cutting the titanium alloy, such as fas tool wear, severe coating shedding, etc. Self-propelled rotary tools improve the chip removal performance and the heat dissipation in the cutting process by the self-propelled insert rotation. Thus the service life of cutters is prolonged and the machined surface defects are inhibited obviously. However, the current researches on self-propelled rotary tools concentrate mainly on turning techniques, while few researches are on milling the titanium alloy. Therefore, in this paper the experimental research was performed on the high-speed milling of TC11 titanium alloy with self-propelled rotary milling cutters (SPRMC), and the cutting performance of cutters was analyzed, based on the milling forces, the tool wear morphology and the wear mechanism. This promotes theoretically widespread application of the technique for milling the titanium alloy with the SPRMC.

\section{Experimental design}

In this paper the corresponding experiment was designed on the high-speed milling of TC11 titanium alloy with the SPRMC, for obtaining the variation laws of the tool wear morphology, the tool wear mechanism, the chip morphology, the milling forces and the machined surface quality with the milling length. The experiment was performed on the VDL-1000E milling center, and the clamped experimental system is shown in Figure 1.

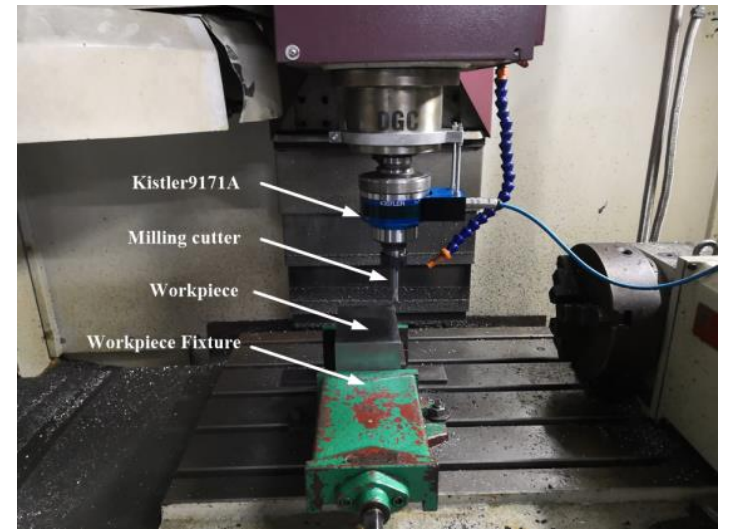

Figure 1 Experimental system

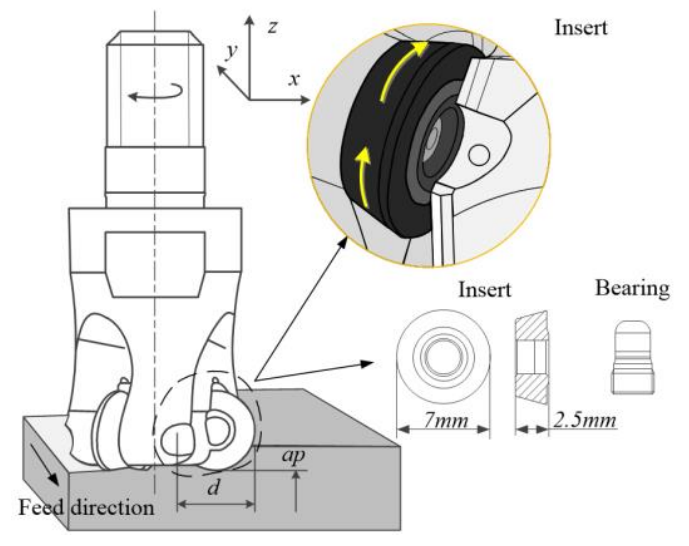

Figure 2 Self-propelled rotary milling cutter

The workpiece material was TC11 titanium alloy, whose chemical composition and physical property are shown in Tables 1 and 2 . The workpiece of a cuboid block was $150 \mathrm{~mm}$ long, 100mm wide and 50mm high. The DR07-8 SPRMC from Hippsc was used in the experiment, as is shown in Figure 2. The circular milling insert was $7 \mathrm{~mm}$ in diameter and $2.5 \mathrm{~mm}$ thick. The substrate material of the insert coated with $\mathrm{TiC}$ was cemented carbide, and the inclination angle was $10^{\circ}$.

Table 1 Chemical composition of TC11 titanium alloy (\%) 


\begin{tabular}{c|c|c|c|c|c}
\hline Elements & $\mathrm{Al}$ & $\mathrm{Mo}$ & $\mathrm{Zr}$ & $\mathrm{Si}$ & $\mathrm{Ti}$ \\
\hline Content & $5.8 \sim 7.0$ & $2.8 \sim 3.8$ & $0.8 \sim 2.0$ & $0.2 \sim 0.35$ & the rest \\
\hline \multicolumn{7}{c}{ Table 2 Physical property of TC11 titanium alloy } \\
\hline $\begin{array}{c}\text { Tensile strength } \\
(\mathrm{MPa})\end{array}$ & $\begin{array}{c}\text { Yield strength } \\
(\mathrm{MPa})\end{array}$ & $\begin{array}{c}\text { Elongation } \\
(\%)\end{array}$ & $\begin{array}{c}\text { Shrinkage } \\
(\%)\end{array}$ & $\begin{array}{c}\text { Density } \\
\left(\mathrm{g} \cdot \mathrm{cm}^{-3}\right)\end{array}$ & $\begin{array}{c}\text { Impact value } \\
\left(\mathrm{J} \cdot \mathrm{cm}^{-2)}\right.\end{array}$ \\
\hline 1030 & 910 & 8 & 23 & 4.5 & 29.5 \\
\hline
\end{tabular}

For observation of the tool wear morphology, the milling forces, the chip morphology and the machined surface quality at different milling lengths, the milling velocity was set as $80 \mathrm{~m} / \mathrm{min}$, the feed per tooth $0.3 \mathrm{~mm} / \mathrm{z}$, the milling depth $0.3 \mathrm{~mm}$, and the milling width $5 \mathrm{~mm}$. Additionally, for exploration of the influence of the milling velocity on the tool wear, the milling velocity was set respectively as $80 \mathrm{~m} / \mathrm{min}, 100 \mathrm{~m} / \mathrm{min}, 120 \mathrm{~m} / \mathrm{min}$, the feed per tooth $0.3 \mathrm{~mm} / \mathrm{z}$, the milling depth $0.3 \mathrm{~mm}$, and the milling width $5 \mathrm{~mm}$. The experiments were performed in the down milling.

In the milling experiments, the Kister9171 A rotary dynamometer was used to collect the data of milling forces. The cutter was removed whenever the milling length reached $3 \mathrm{~m}$. Then the VHX-1000 ultra-depth three-dimensional microscope (UDTDM) was used for observation of the rake and flank wear morphology, the SU3500 scanning electron microscope (SEM) was used to detect the morphology and the elements of the wear area, and the Taylor CCI profilometer was used for detecting the surface morphology and roughness of the retained workpiece. The experiment was not stopped until the flank wear width reached $300 \mu \mathrm{m}$ or obvious damage happened to the insert. Moreover, the chips were collected at different milling lengths, and then the denture acrylic and epoxy resin were used for inlaid sample preparation, grinding and polishing of the collected chips. Finally the macromorphology and micromorphology of chips were observed respectively by the VHX-1000 UDTDM and the SU3500 SEM.

\section{Experimental results and discussion}

\subsection{Analysis of tool wear}

Figure 3 shows the variation in the rake wear morphology of the SPRMC at different milling lengths. When the milling length reached $9 \mathrm{~m}$, the scratches were observed on the local rake face of the insert. Afterwards the scratched area was evenly distributed and gradually expanded along the circumference of the cutting edge. As the milling length increased, the coating peeled gradually off and weakened its protection for the insert. Consequently, the friction between insert and chip intensified gradually and plenty of scratches and grooves in the radial direction occurred on the rake face. 


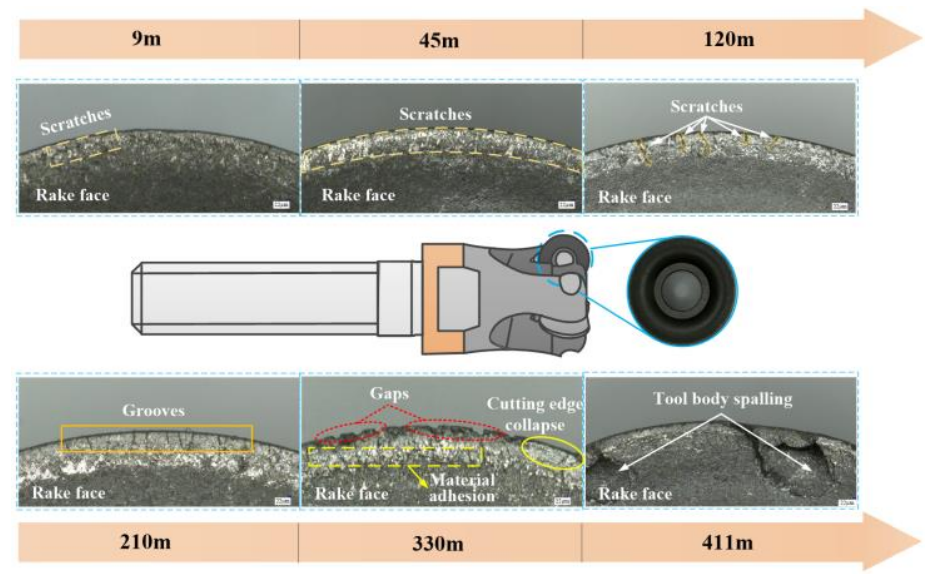

Figure 3 Rake wear morphology of the self-propelled rotary milling cutter

As the cutting proceeded, under the influence of strong friction and mechanical impact, quantities of gaps appeared on the cutting edge and the extensive material adhesion occurred on the rake face, accompanied by the abrasions to the local substrate material of the insert. The occurrence of gaps damaged the continuous smooth rotation of the SPRMC insert and caused stronger friction and mechanical impact, and thus the cutting stability was reduced. When the milling length reached $411 \mathrm{~m}$, the extensive substrate materials peeled off the rake face, and here the cutter could no longer work.

Figure 4 shows the variation in the flank wear morphology of the SPRMC at different milling lengths. When the milling length reached $9 \mathrm{~m}$, the slight scratches occurred on the flank face of the insert. With the increase of the milling length, the scratched area expanded constantly in the radial direction, and the obvious radial scratches appeared on the flank face. As the cutting proceeded, the evident workpiece material adhesion happened to the flank face, and the adhesive area was extended with the increase of the milling length. With the aggravation of the tool wear, the adhesive workpiece material was taken away by chips, and so stronger friction was generated. Thus lots of grooves in different depths emerged on the flank face and the dense notches formed on the cutting edge. During the long machining, the constant rotation of the insert exerted the cyclical thermal fluctuation and mechanical impact on all parts of the cutting edge, finally resulting in the coating peeling.

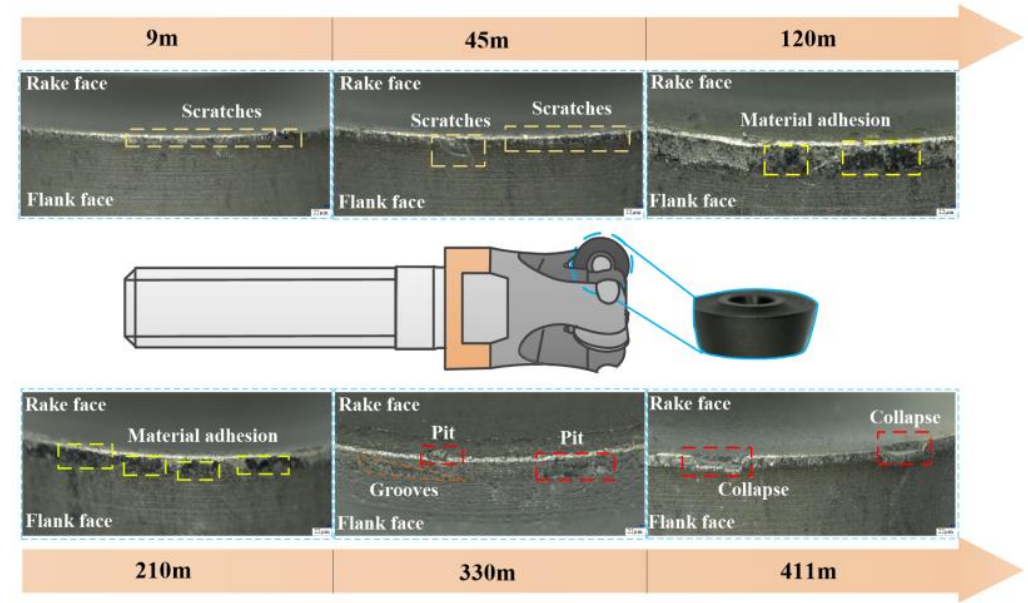

Figure 4 Flank wear morphology of the self-propelled rotary milling cutter

\subsection{Analysis of tool wear mechanism}


Figure 5 shows the tool wear morphology of the SPRMC at a milling length of $45 \mathrm{~m}$. The dense scratches in different depths were clearly observed on the rake face. It was found by the energy spectrum analysis that $\mathrm{Al}$ and $\mathrm{O}$ as well as $\mathrm{C}$ and $\mathrm{Ti}$ elements existed in the coating material, as is shown in Figure 5(b). This indicated that the abrasive wear mechanism acted prominently at a small milling length. The main reason is that the strong friction between insert and workpiece results in the coating shedding, and the scraping effect of hard spots in the shed coating causes the scratches on the tool surface.

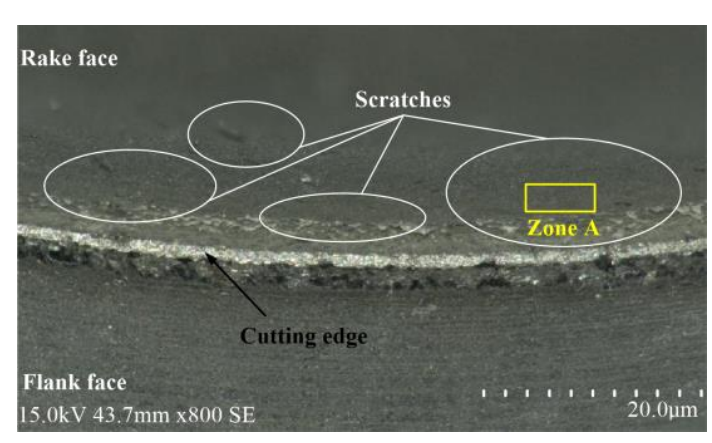

(a) Cutting edge wear morphology

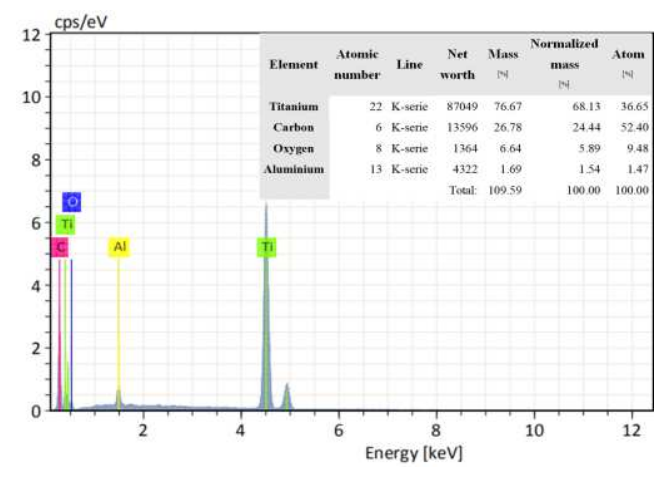

(b) Energy spectrum analysis of Zone A

Figure 5 Tool wear morphology of the self-propelled rotary milling cutter at a milling length of $45 \mathrm{~m}$

Figure 6 presents the tool wear morphology of the SPRMC at a milling length of $120 \mathrm{~m}$. With continuous increase of the milling length, the frequent friction and mechanical impact weakened obviously the adhesive force between coating and substrate, and caused the cracks in the area of concentrated loads, otherwise reducing the adhesive force between coating and substrate, shown in Figure 6(a). Thus the coating peeled evenly off the rake face. For further reasons, the coating and substrate material differ in the elastic modulus and the thermal expansion coefficient, and the thermodynamic load acts jointly. Therefore, the internal stress is generated between coating and substrate. When the internal stress exceeds the adhesive force between coating and substrate, the coating will peel partially and the cemented carbide substrate will be exposed.

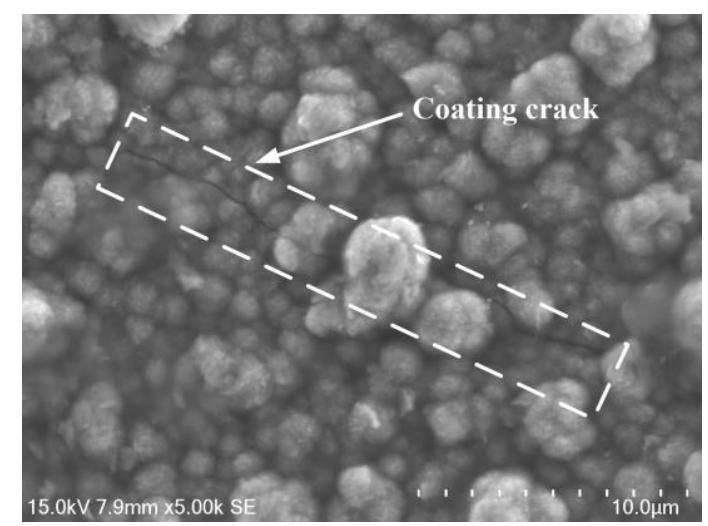

(a) Coating cracks

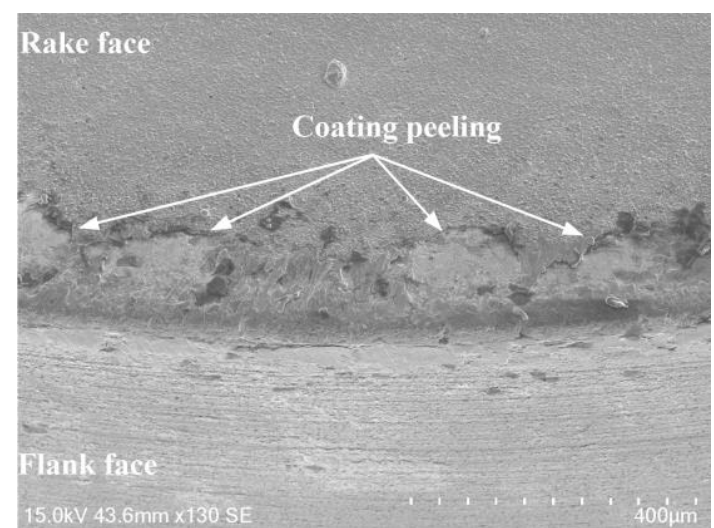

(b) Coating peeling

Figure 6 Tool wear morphology of the self-propelled rotary milling cutter at a milling length of $120 \mathrm{~m}$

The tool wear morphology of the SPRMC at a milling length of 210m is shown in Figure 7. It was found by observing the wear area of the cutting edge that the regular adhesive areas appeared on both rake and flank faces of the insert. As the cutting proceeded, the adhesive areas were taken away by chips, and thus the insert substrate was exposed, as is shown in Figure 7(a). Based on the energy spectrum analysis, quantities of elements contained in the workpiece, such as $\mathrm{Ti}, \mathrm{Al}, \mathrm{Mo}$ 
and $\mathrm{Zr}$, were observed in adhesive Zone B, shown in Figure 7(c). Then the further energy spectrum analysis was made of worn Zone $\mathrm{C}$ on the flank face and unworn Zone $\mathrm{A}$, as is shown in 7(d) and 7(b). Only the elements contained in the coating material (Ti, C, etc.) were found in unworn Zone A, while plenty of elements contained in the substrate material (W, Co, etc.) were found in worn Zone $\mathrm{C}$, but the elements contained in the workpiece (Ti, Al, Mo , Zr, etc.) were not observed. Thus the adhesive wear occurred obviously on the insert.

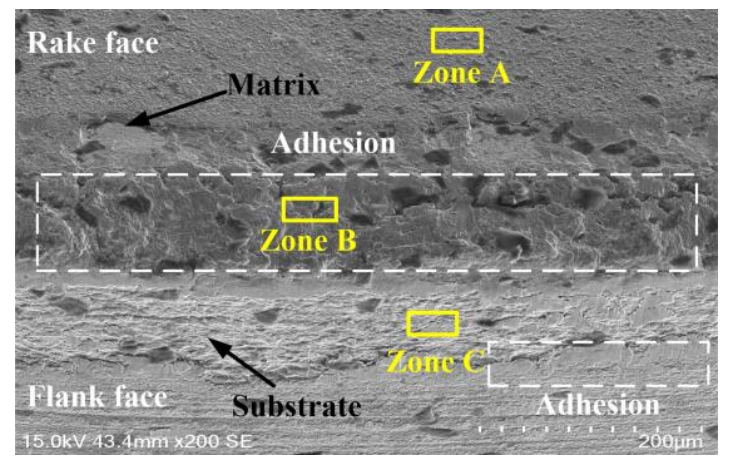

(a) Cutting edge wear morphology

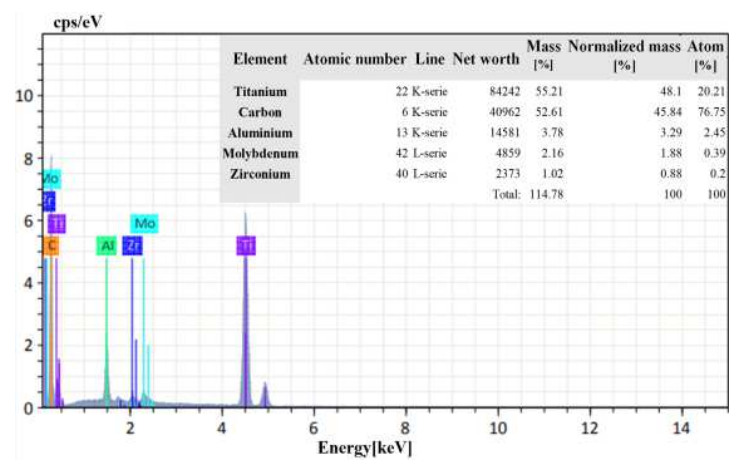

(c) Energy spectrum analysis of Zone B

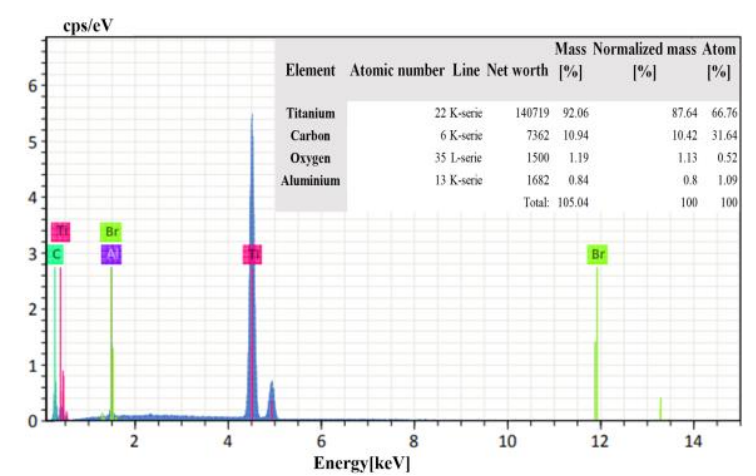

(b) Energy spectrum analysis of Zone A

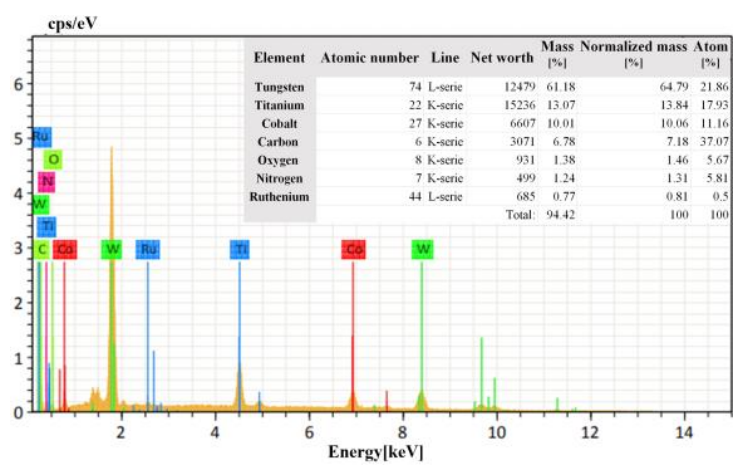

(d) Energy spectrum analysis of Zone C

Figure 7 Tool wear morphology of the self-propelled rotary milling cutter at a milling length of $210 \mathrm{~m}$

Figure 8 shows the tool wear morphology of the SPRMC at a milling length of $330 \mathrm{~m}$. The thermal fatigue cracks in the radial direction were observed clearly on the insert. The reason is that in milling TC11 titanium alloy with the SPRMC, the constant self-propelled insert rotation involved alternately all parts of the cutting edge in cutting, so the cutting edge experienced regularly heating and cooling, and finally the cyclical temperature fluctuation caused the radial thermal fatigue cracks on the insert. Here the tool wear mechanism has turned into a fatigue wear mechanism. As the cutting proceeded continuously, the number of cracks rose with increase of the milling length and eventually a crack network formed. Consequently the cutting performance and the strength of the insert dropped sharply. 


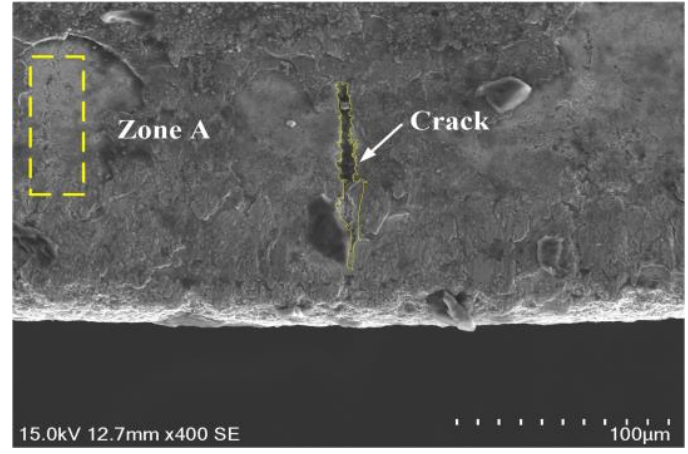

(a) Crack morphology on the cutter surface

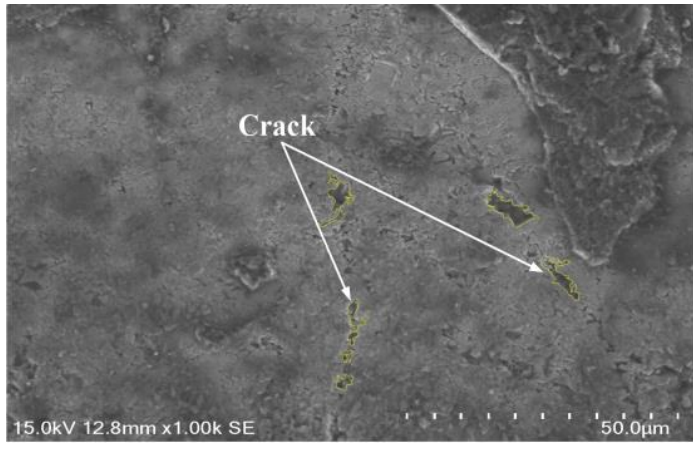

(b) Magnified crack morphology in Zone A

Figure 8 Tool wear morphology of the self-propelled rotary milling cutter at a milling length of $330 \mathrm{~m}$

Figure 9 displays the tool wear morphology of the SPRMC at a milling length of $411 \mathrm{~m}$. The occurrence of the thermal cracks on the insert largely reduced the bonding strength between the insert materials, and thus the insert material peeled off under the frequent impact of mechanical load. The peeling damaged the continuous insert rotation and will results in stronger friction and mechanical impact. Therefore, given the machined surface quality, the cutter can no longer be used.
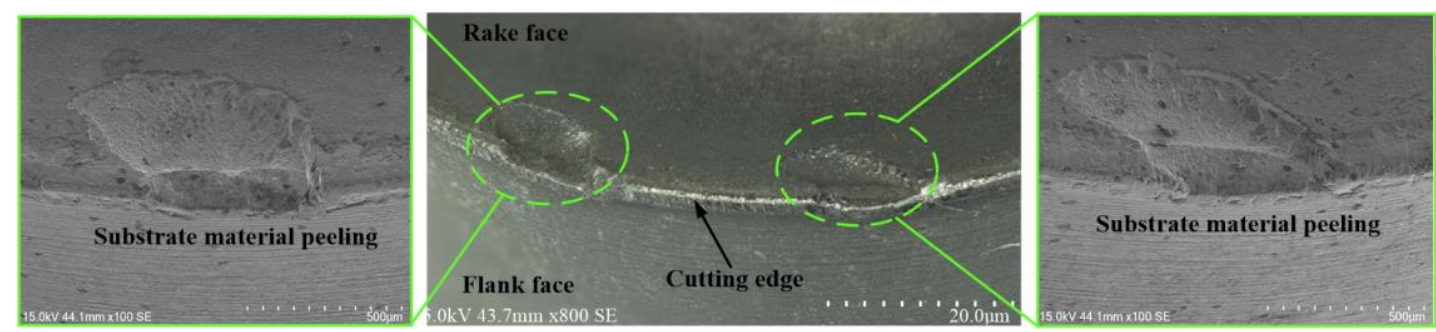

Figure 9 Tool wear morphology of the self-propelled rotary milling cutter at a milling length of $411 \mathrm{~m}$

\subsection{Influence of tool wear on milling forces and chips}

Figure 10 reveals the variation in the milling forces and the chip morphology at different milling lengths when the SPRMC was used for milling TC11vtitanium alloy. It can clearly be observed from the figure that with continuous increase of the milling length, the milling forces all showed a similar tendency to rise constantly. Among them the tangential force was the largest and the radial force the smallest. In the early and middle stages of milling, the milling forces grew relatively slow. This has something to do with the improvement in the tool wear resistance made by the self-propelled insert rotation. The milling forces increased significantly after the milling length reached $330 \mathrm{~m}$. This is because the severe tool wear caused the cutting performance and stability to drop off. 


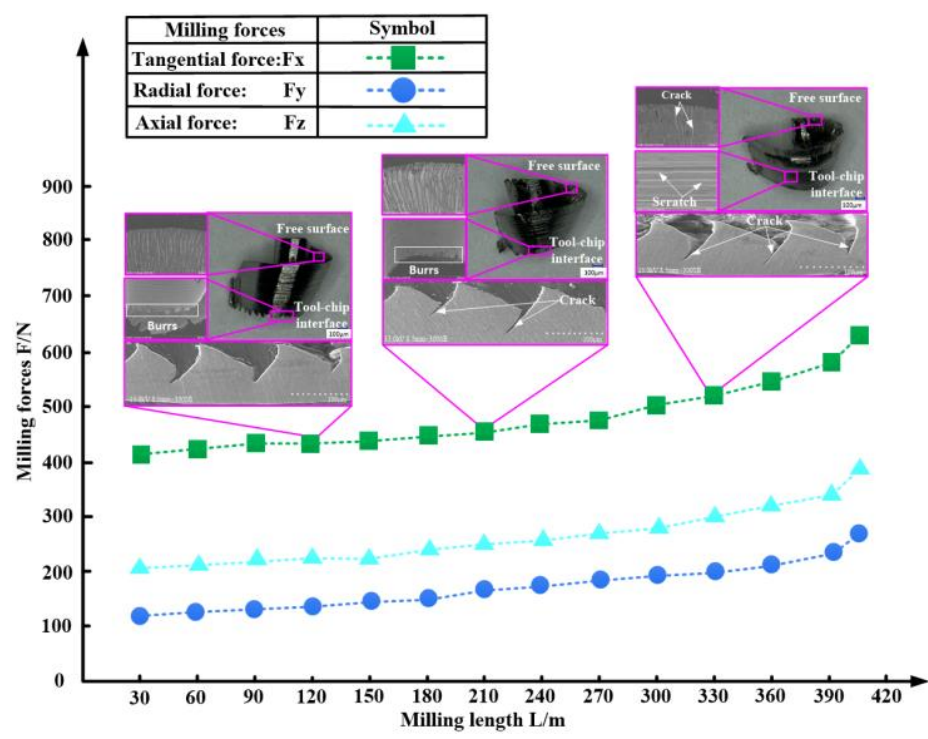

Figure 10 Variation of milling forces and chip morphology at different milling lengths

As the milling length increased, the curling degree of chips diminished gradually, and the folds on the free chip surface became increasingly irregular, meanwhile accompanied by obvious cracks. Furthermore, the burrs on both sides of the chip grew gradually inconsistent in the morphology, and the interface between insert and chip turned less and less smooth and showed the obvious scratches. Moreover, the obvious cracks occurred at the bottom of the chip; the number of cracks was directly proportional to the milling length; the sawteeth of the chip were well distributed. This is because the tool wear aggravation, resulting from the increase in the milling length, reduced the cutting stability. Meanwhile this decreased the shear effect of the insert on the workpiece and intensified the extrusion effect, and thus the chip deformation further worsened.

\subsection{Influence of tool wear on surface quality}

When the SPRMC was used to mill TC11 titanium alloy, the machined surface roughness varied with the milling length, as is shown in Figure 11. In the early and middle stages of milling, as the milling length increased constantly, there was a tendency for the machined surface roughness to worsen slowly, but it was found by observing its 3D morphology that the machined surface still remained regular and smooth. However, when the milling length increased to $330 \mathrm{~m}$, the machined surface became gradually uneven, being accompanied by some damage on it. The main reason for the obvious decrease in the surface quality is that the tool wear grows severe, the notches occur on the cutting edge and the insert substrate peels off. 


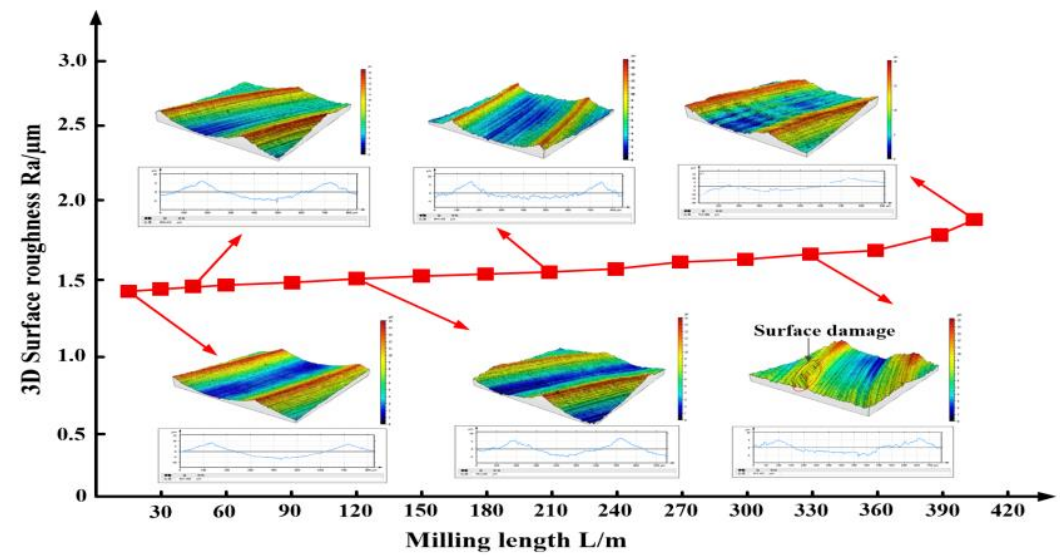

Figure 11 Varying curves of the machined surface roughness with the milling length

\subsection{Analysis of the influence of milling velocity on milling process}

Figure 12 shows the tool wear curves of the SPRMC at different milling velocities. In milling TC11 titanium alloy with the SPRMC at the different milling velocities of $80 \mathrm{~m} / \mathrm{min}, 100 \mathrm{~m} / \mathrm{min}$ and $120 \mathrm{~m} / \mathrm{min}$, the flank wear presented an approximately linear increase with extension of the milling length. Additionally, the acceleration of the milling velocity worsened gradually the tool wear, and particularly when the milling velocity accelerated to $120 \mathrm{~m} / \mathrm{min}$ the insert started peeling and even failing prematurely. The reason for accelerating the insert failure is that too high milling velocity makes each part of the edge involved in cutting come into more frequent contact with the workpiece, and thus the thermal and mechanical impacts are more frequently exerted on the insert.

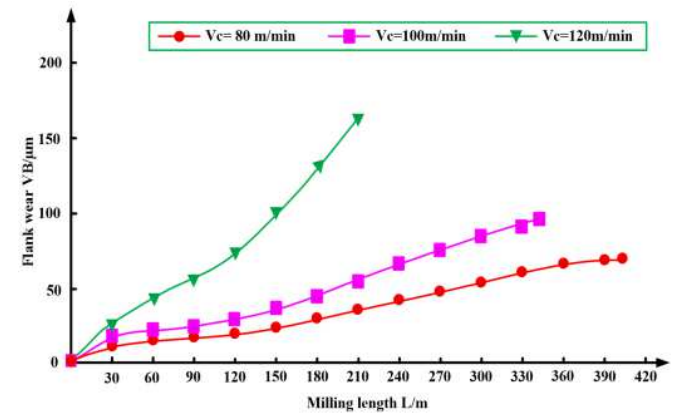

Figure 12 Tool wear curves of the SPRMC at different milling velocities

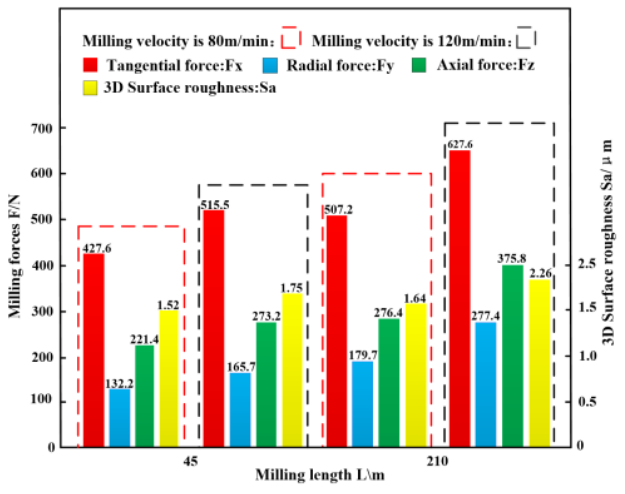

Figure 13 Comparison of the milling forces and surface roughness at different milling lengths

Figure 13 presents the comparison of the same milling forces and the comparison of surface roughness at different milling lengths when the SPRMC was used for milling TC11 titanium alloy. In the same milling stroke, all the milling forces at the milling velocity of $120 \mathrm{~m} / \mathrm{min}$ were a little larger than the ones at $80 \mathrm{~m} / \mathrm{min}$. As the milling length was extended, both the milling forces and the surface roughness were on the less and slower increase at the milling velocity of $80 \mathrm{~m} / \mathrm{min}$. This is mainly because in milling TC11 titanium alloy with the SPRMC at the velocity of $80 \mathrm{~m} / \mathrm{min}$, the tool is slowly worn to a lesser degree, the milling process is relatively stable, and the milling forces and the surface roughness both remain at a lower level. 


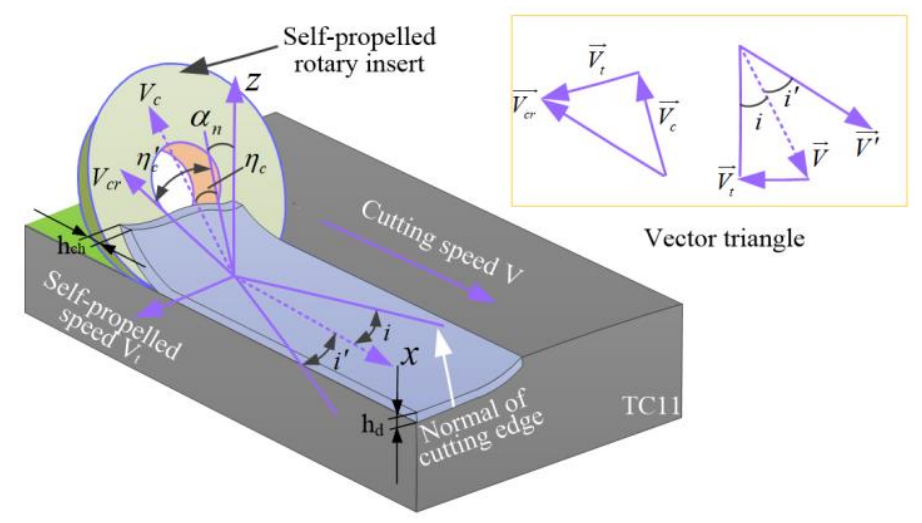

Figure 14 The state of high-speed milling of TC11titanium alloy with the SPRMC

Figure 14 shows the state of the high-speed milling of TC11 titanium alloy with the SPRMC. It can be seen from the figure that the SPRMC movement consisted of the cutter rotation and the self-propelled insert rotation. Here $V_{t}$ stands for the self-propelled rotary insert velocity, $V$ the milling velocity, $i$ the inclination angle, $i^{\prime}$ the inclination angle increase (caused by the self-propelled insert rotation), $\alpha_{n}$ the normal rake angle, $\eta_{c}$ the chip flow angle (formed when the insert is fixed), and $\eta_{c}^{\prime}$ the chip flow angle (formed when the insert is in self-propelled rotation).

Furthermore, $\mathrm{C}$ is defined as the ratio of the self-propelled rotary velocity of the insert $V_{t}$ to the milling velocity $V$. Without considering the influence of some factors, such as the friction resistance from bearings, the rotational inertia of all rotating parts, etc. the ideal $\mathrm{C}$ value is approximately equal to $\sin i$. However, in the actual machining, the self-propelled insert rotation caused the inclination angle increase $i^{\prime}$, expressed as Exps. (1).

$$
i^{\prime}=\arctan \left[\frac{V_{t} / V \times \cos i}{1+V_{t} / V \times \sin i}\right]=\arctan \left[\frac{\cos i}{\frac{1}{C}+\sin i}\right]
$$

The chip flow angle (formed when the insert is in self-propelled rotation.) is expressed as Exps. (2).

$$
\tan \eta_{c}^{\prime}=\tan \eta_{c}+\frac{\xi_{t} \tan i^{\prime}}{\cos i\left(\cos i-\tan i^{\prime} \sin i\right)}
$$

In the expression, $\xi_{t}$, the coefficient of chip thickness deformation, stands for the ratio of chip thickness $\mathrm{h}_{\mathrm{ch}}$ to milling thickness $\mathrm{h}_{\mathrm{d}}$.

Figures 15 (a) and (b) display the rake wear morphology using the SPRMC to mill TC11 titanium alloy till $45 \mathrm{~m}$ long, respectively at the milling velocity of $80 \mathrm{~mm} / \mathrm{min}$ and $120 \mathrm{~mm} / \mathrm{min}$. It was found by comparison that the chip flow angle $\eta_{c}^{\prime}$ was smaller at $120 \mathrm{~mm} / \mathrm{min}$ when the chip removal resistance was larger, and thus the insert was worn faster. 


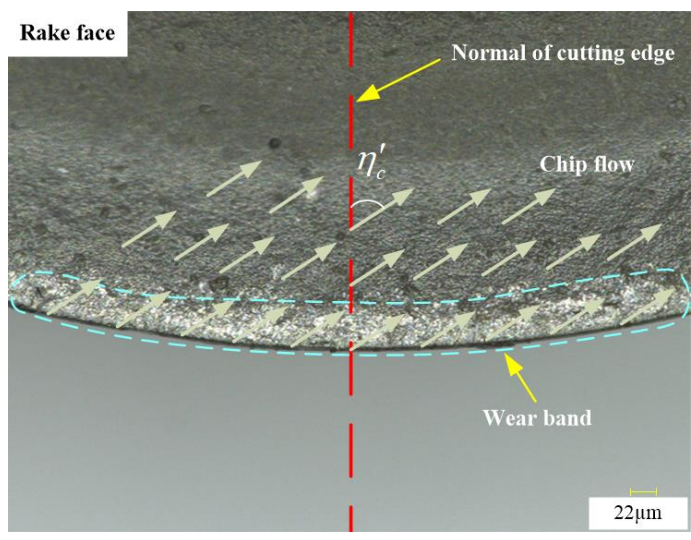

(a) $80 \mathrm{~m} / \mathrm{min}$

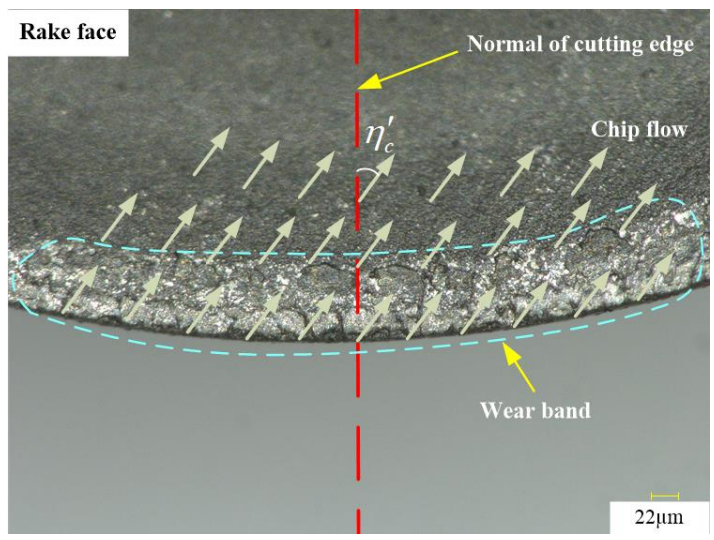

(b) $120 \mathrm{~m} / \mathrm{min}$

Figure 15 Rake wear morphology at a milling length of $45 \mathrm{~m}$ at different milling velocities

In milling TC11 titanium alloy with the SPRMC, the self-propelled insert rotation dissipated cutting heat more easily, so the metal softening effect did not obviously occur or decrease the milling forces. On the contrary, the milling forces all increased. The reasons for the increase in milling forces are that with the acceleration in milling velocity the friction resistance between insert and chip intensifies, while the ratio $\mathrm{C}$ of the self-propelled rotary velocity of the insert to the milling velocity diminishes. Consequently both the inclination angle and the chip flow angle lessen. Subsequently, as the milling stroke extended, the tool wear occurred, the cutting edge became blunt, and the ratio $\mathrm{C}$ of the self-propelled rotary velocity of the insert to the milling velocity further lessened. Therefore, greater milling forces were generated.

\section{Conclusion}

In this paper, an experimental study was conducted on the high-speed milling of TC11 titanium alloy with the SPRMC, and the influence of milling velocity on tool wear and milling forces was analyzed. Consequently, the variation laws of milling forces, chip morphology and machined surface quality with the milling length have been obtained. The conclusions are drawn as follows.

1. In the early and middle stages of milling, under the joint action of the abrasive and adhesive wear mechanisms, both rake and flank coatings of the SPRMC peel evenly, and are simultaneously accompanied by the obvious scratches, grooves and adhesion.

2. Due to the cyclical thermodynamic impact, the tool wear of the SPRMC worsens and develops gradually to the breakage stage, but dominated by the fatigue wear mechanism. Meanwhile, the dense notches and the thermal fatigue cracks occur on the cutting edge, and thus the insert starts peeling and failing evidently.

3. There is a tendency for all milling forces to rise as the milling length is extended, and the acceleration of the milling velocity causes the obvious increase in all milling forces. The chip deformation deteriorates gradually with the increase in the milling length, and the folds on the free chip surface turn irregular. Moreover the interface between tool and chip gets unsmooth with obvious scratches, and the evident cracks form at the bottom of chips, accompanied by ill-distributed saw-teeth.

4. The continuous increase of milling length causes stronger friction and mechanical impact, and thus the smooth surface machined by the SPRMC grows gradually rough. As a result, the machined surface quality declines clearly. Additionally, the acceleration in milling velocity 
increases both the tool wear rate and the machined surface roughness evidently.

Ethical Approval The research does not involve human participants or animals and the authors warrant that the paper fulfills the ethical standards of the journal.

Consent to Participate It is confirmed that all the authors are aware and satisfied of the authorship order and correspondence of the paper.

Consent to Publish All the authors are satisfied that the last revised version of the paper is published without any change.

Author contributions, Lu Yujiang has designed the experiments, conducted the experiments, collected and analyzed data, and written the manuscript; Chen Tao has organized the project, designed the experiments, and written the manuscript.

Funding This work was financially supported by the National Natural Science Foundation of China (Grant No. 51975168).

Competing Interests The authors declare that they have no competing interests.

Availability of data and materials The raw/processed data required to reproduce these findings cannot be shared for the time being. Data will be made available upon request.

\section{References}

[1] Carou D, Rubio EM, Herrera J, Lauro CH, Davim JP (2017) Latest advances in the micro-milling of titanium alloys: a review. Procedia Manufacturing 13: 275-282.

[2] Ulutan D, Ozel T (2011) Machining induced surface integrity in titanium and nickel alloys: A review. International Journal of Machine Tools \& Manufacture 51(3): 250-280.

[3] Singh R, Khamba JS (2006) Ultrasonic machining of titanium and its alloys: A review. Journal of Materials Processing Technology 173(2): 125-135.

[4] Thakur A, Gangopadhyay S (2016) State-of-the-art in surface integrity in machining of nickel-based super alloys. International Journal of Machine Tools \& Manufacture 100: 25-54.

[5] Niu BY, Sun J, Yang B (2020) Multisensory based tool wear monitoring for practical applications in milling of titanium alloy. Materials Today: Proceedings 22: 1209-1217.

[6] Joy N, Prakash S, Krishnamoorthy A, Antony A (2020) Experimental investigation and analysis of drilling in Grade 5 Titanium alloy (Ti-6Al-4V). Materials Today: Proceedings 21(1): 335-339.

[7] Sun H, Xiao H, Li L (2016) Experimental Study on Cutting Force and Cutting Power in High Feed Milling of Ti5A15Mo5VCrFe. Materials Science Forum 836-837: 88-93.

[8] Rashid RAR, Palanisamy S, Sun S, Dargusch MS (2016) Tool wear mechanisms involved in crater formation on uncoated carbide tool when machining Ti6Al4V alloy. The International Journal of Advanced Manufacturing Technology 83(9): 1457-1465.

[9] Koseki S, Inoue K, Sekiya K, Morito S, Ohba T, Usuki H (2016) Wear Mechanisms of PVD-Coated Cutting Tools During Continuous Turning of Ti-6Al-4V Alloy. Precision 
Engineering 47: 434-444.

[10] Daymi A, Boujelbene M, Amara AB, Bayraktar E, Katundi D (2011) Surface integrity in high speed end milling of titanium alloy Ti-6Al-4V. Materials Science \& Technology 27(1): 387-394.

[11] Yang FZ, Meng GY, Zhao J, Ai X (2009) Fabrication of WC matrix composite tool material and its cutting performance in machining titanium alloys. Tsinghua Science \& Technology 14(2): 75-78.

[12] Tan DW, Chen ZW, Wei WX, Song BC, Guo WM, Lin HT, Wang CY (2020) Wear behavior and mechanism of $\mathrm{TiB}_{2}$-based ceramic inserts in high-speed cutting of Ti6Al4V alloy. Ceramics International 46(6): 8135-8144.

[13] Chowdhury MSI, Bose B, Yamamoto K, Shuster LS, Veldhuis SC (2020) Wear performance investigation of PVD coated and uncoated carbide tools during high-speed machining of TiAl6V4 aerospace alloy. Wear 446-447.

[14] Wang GY, Liu XL, Gao WJ, Yan BX, Chen T (2019) Study on the Design and Cutting Performance of a Revolving Cycloid Milling Cutter. Applied Sciences 9(14): 2915.

[15] Wang GY, Liu XL, Chen T, Gao WJ (2020) An Experimental Study on Milling Titanium Alloy with a Revolving Cycloid Milling Cutter. Applied Sciences 10(4): 1423.

[16] Lei ST, Liu WJ (2002) High-speed machining of titanium alloys using the driven rotary tool. International Journal of Machine Tools and Manufacture 42(6): 653-661.

[17] Olgun O,Budak E (2013) Machining of Difficult-to-Cut-Alloys Using Rotary Turning Tools. Procedia CIRP 8: 81-87.

[18] Li L, Kishawy HA (2006) A model for cutting forces generated during machining with self-propelled rotary tools. International Journal of Machine Tools and Manufacture 46(12-13): 1388-1394.

[19] Kishawy HA, Pang L, Balazinski M (2011) Modeling of tool wear during hard turning with self-propelled rotary tool. International Journal of Mechanical Sciences 53(11): 1015-1021.

[20] Kishawy HA, Li L, EL-Wahab AI (2006) Prediction of chip flow direction during machining with self-propelled rotary tools. International Journal of Machine Tools and Manufacture 46(12-13): 1680-1688.

[21] Kossakowska J, Jemielniak K (2012) Application of Self-Propelled Rotary Tools for Turning of Difficult-to-machine Materials. Procedia CIRP 1: 425-430.

[22] Dessoly V, Melkote SN, Lescalier C (2004) Modeling and verification of cutting tool temperatures in rotary tool turning of hardened steel. International Journal of Machine Tools and Manufacture 44(14): 1463-1470.

[23] Ezugwu EO, Olajire KA, Wang ZM (2002) Wear evaluation of a self-propelled rotary tool when machining titanium alloy IMI 318. Proceedings of the Institution of Mechanical Engineers-Part B-Engineering Manufacture 216: 891-897.

[24] Ezugwu EO(2007) Improvements in the machining of aero-engine alloys using self-propelled rotary tooling technique. Journal of Materials Processing Technology 185(1-3): 60-71. 
Figures

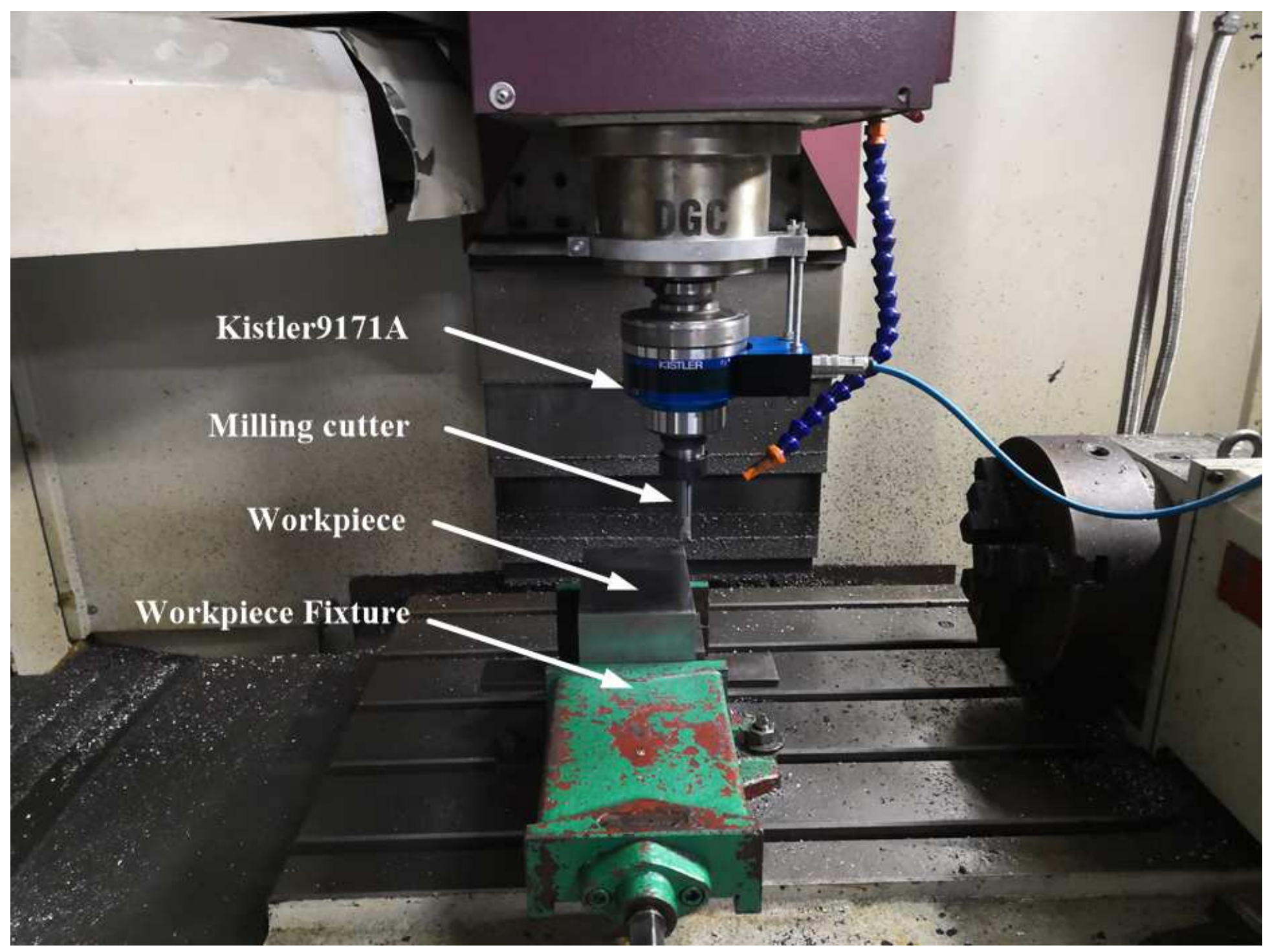

Figure 1

Experimental system 


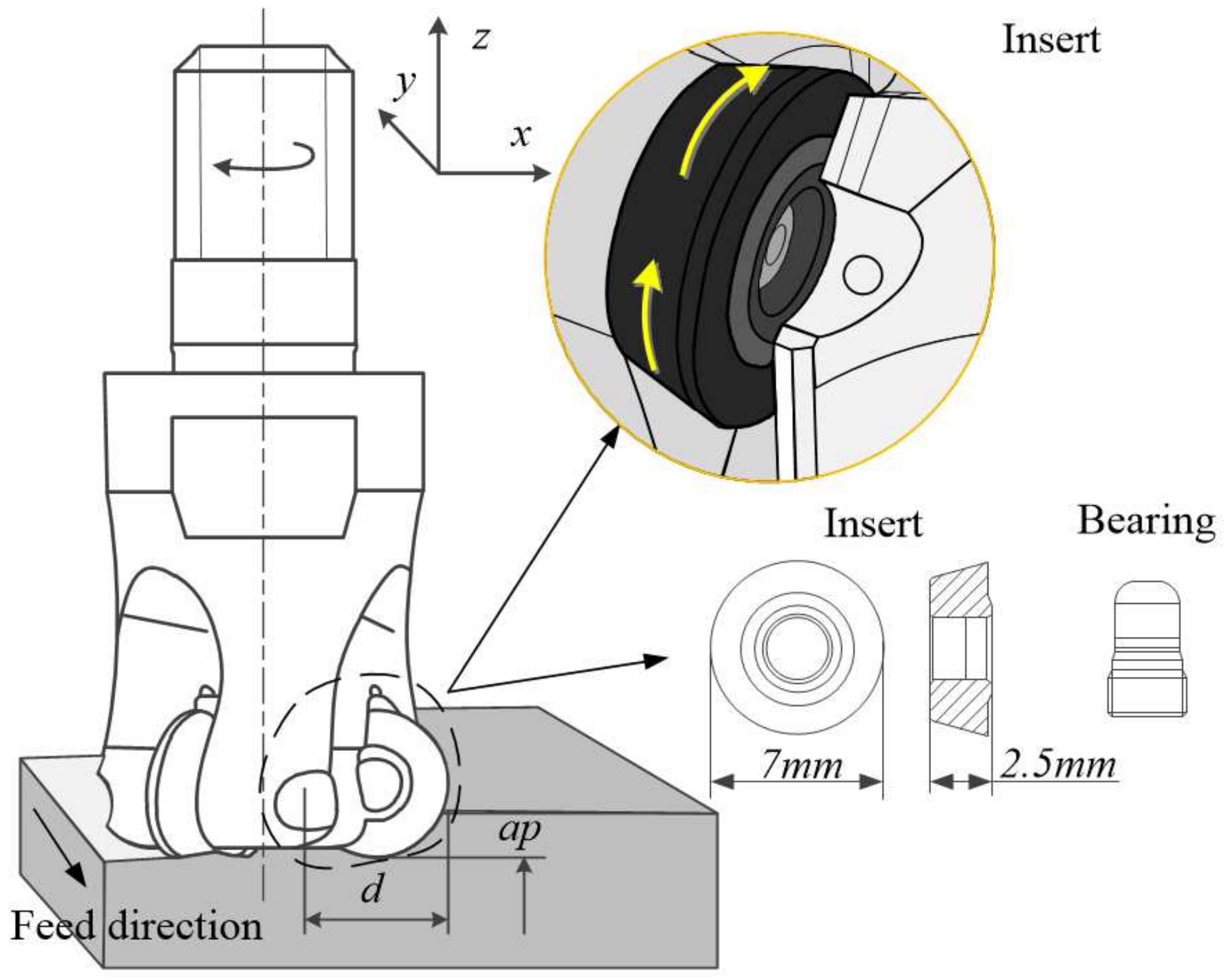

Figure 2

Self-propelled rotary milling cutter 


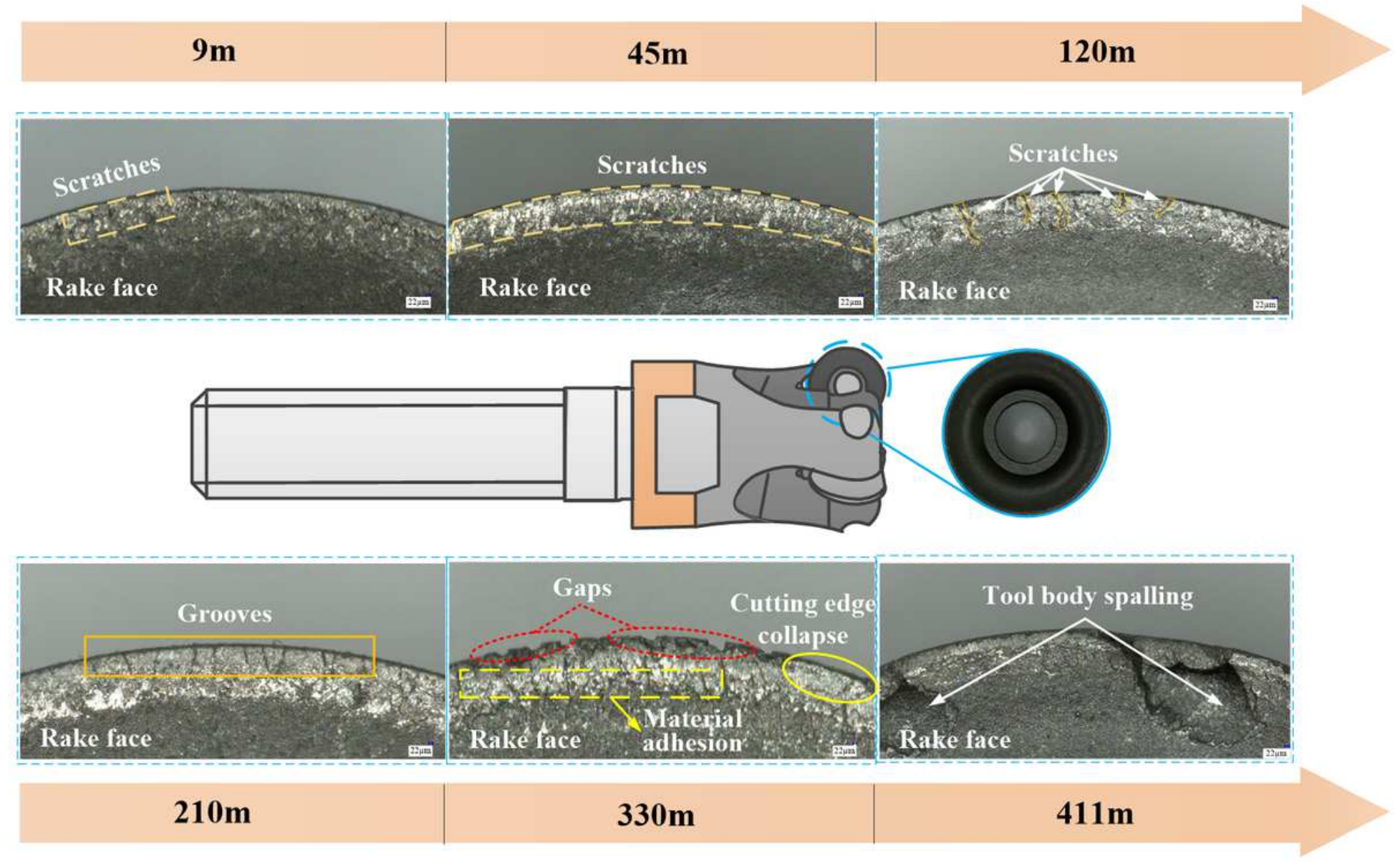

\section{Figure 3}

Rake wear morphology of the self-propelled rotary milling cutter 


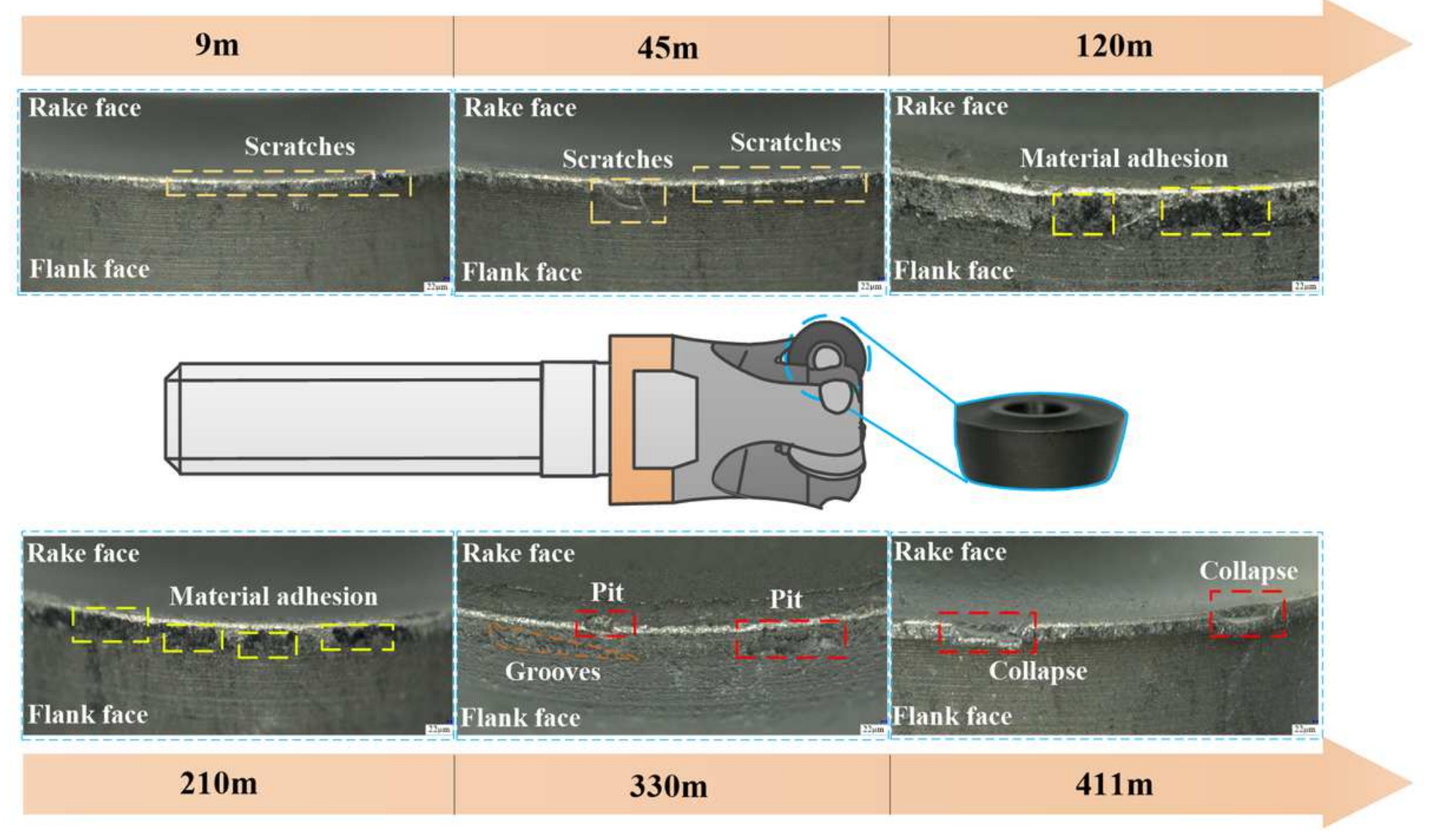

\section{Figure 4}

Flank wear morphology of the self-propelled rotary milling cutter

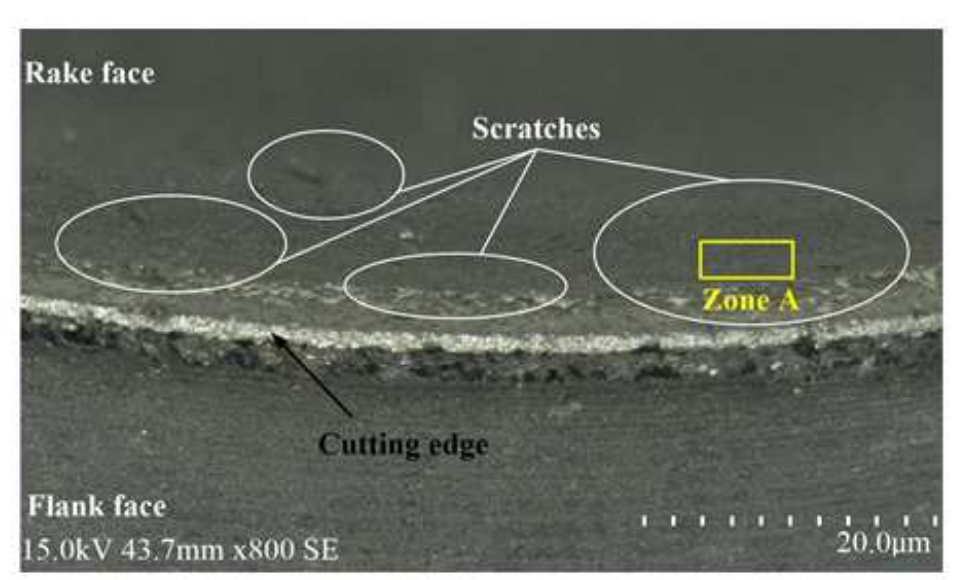

(a) Cutting edge wear morphology

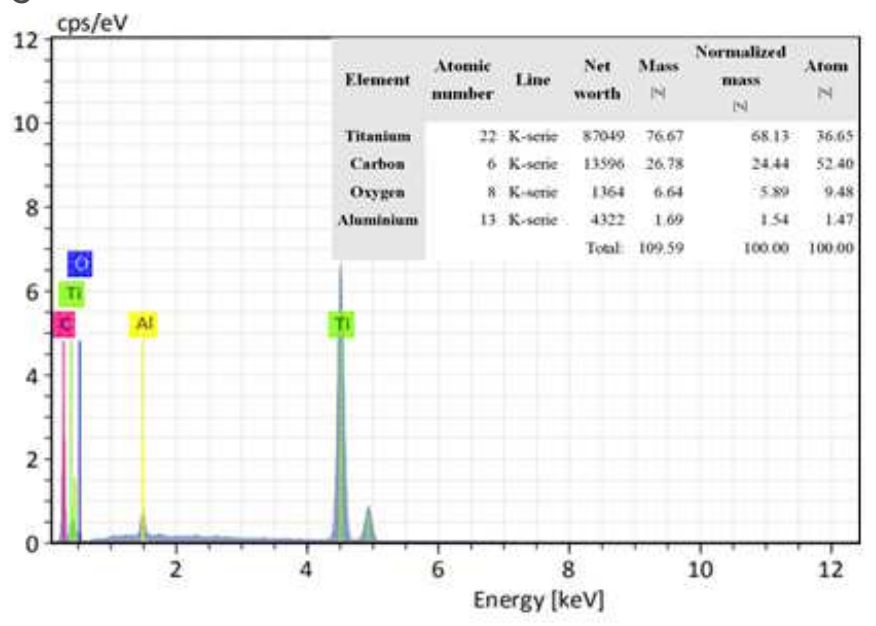

(b) Energy spectrum analysis of Zone A

\section{Figure 5}

Tool wear morphology of the self-propelled rotary milling cutter at a milling length of $45 \mathrm{~m}$ 


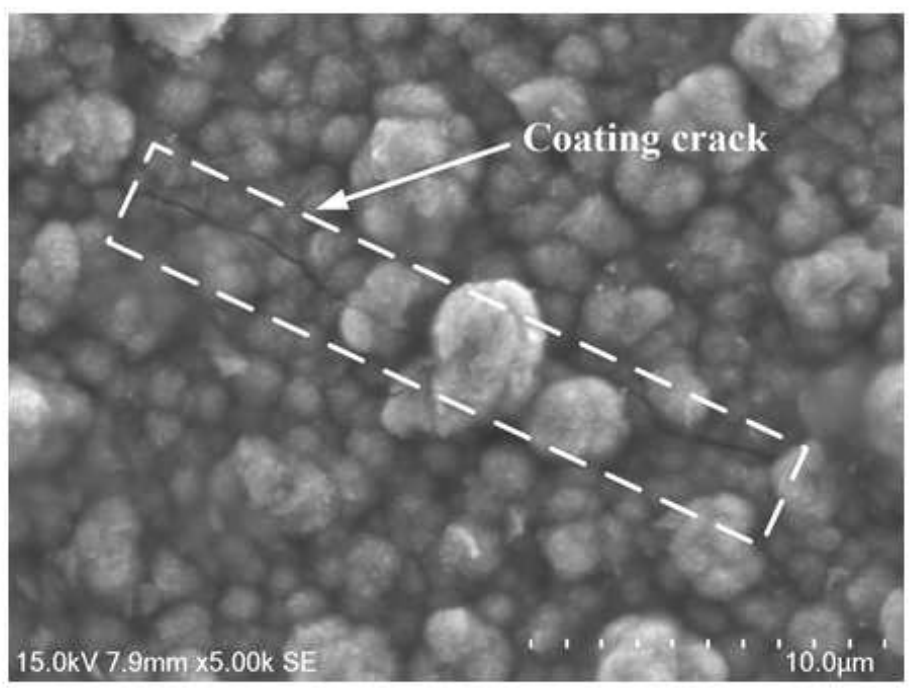

(a) Coating cracks

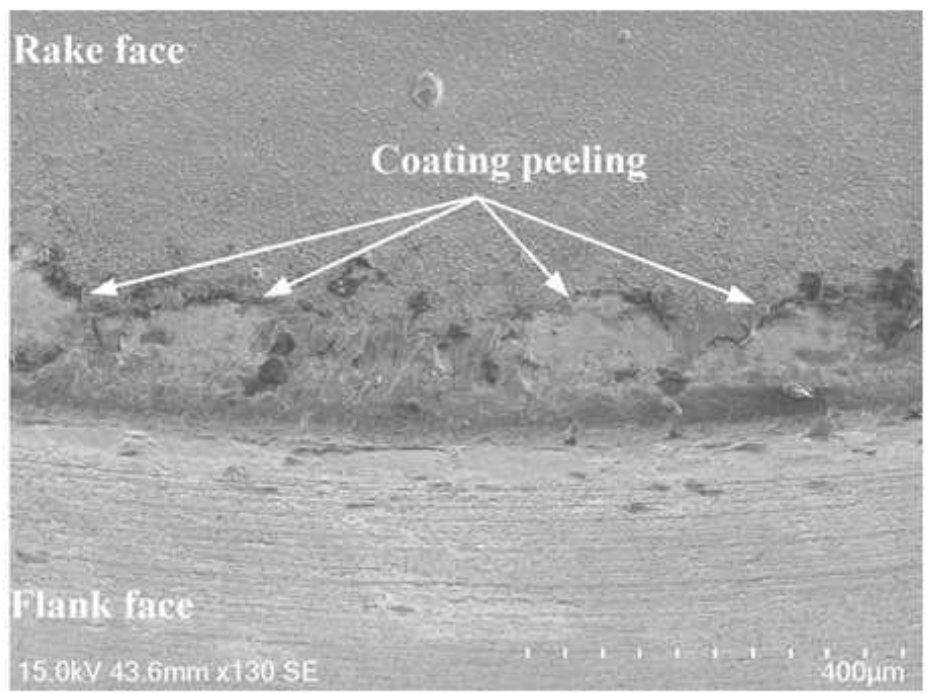

(b) Coating peeling

\section{Figure 6}

Tool wear morphology of the self-propelled rotary milling cutter at a milling length of $120 \mathrm{~m}$

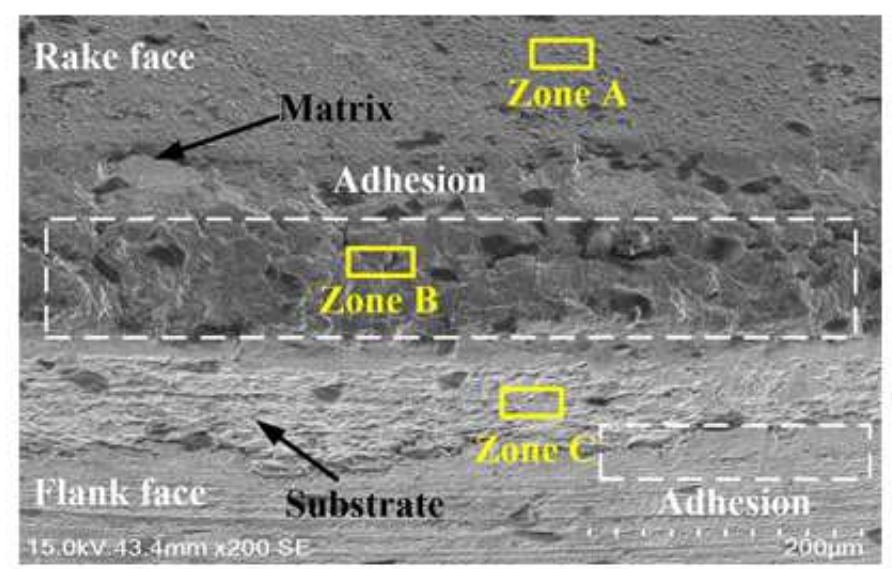

(a) Cutting edge wear morphology

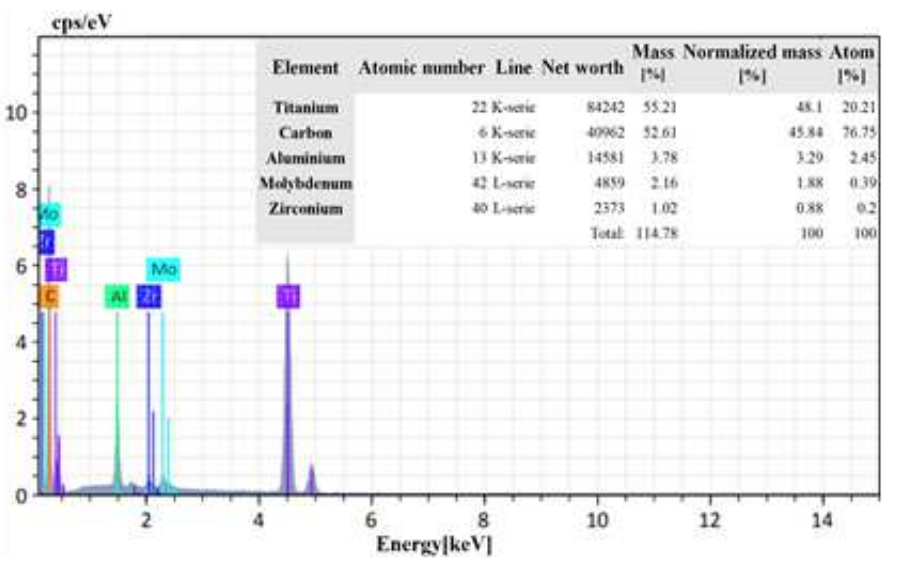

(c) Energy spectrum analysis of Zone B

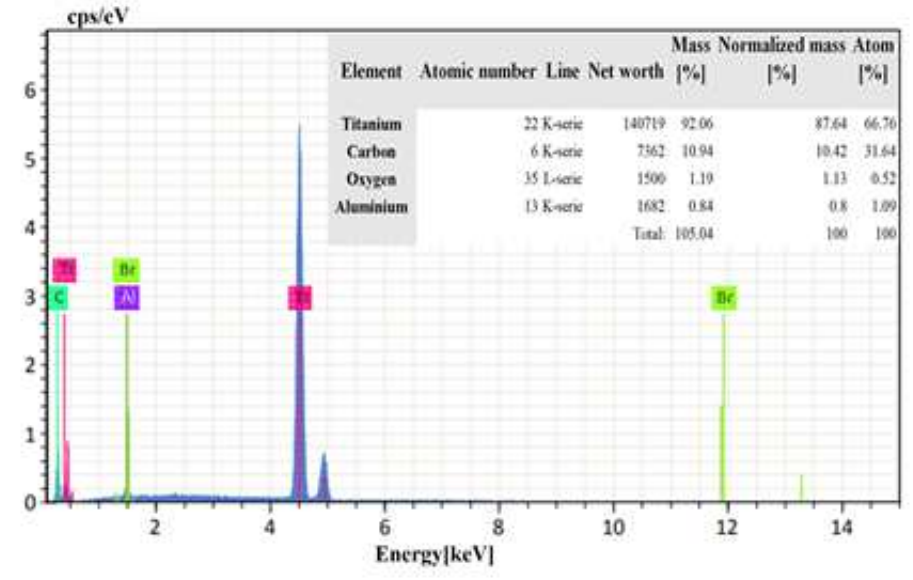

(b) Energy spectrum analysis of Zone A

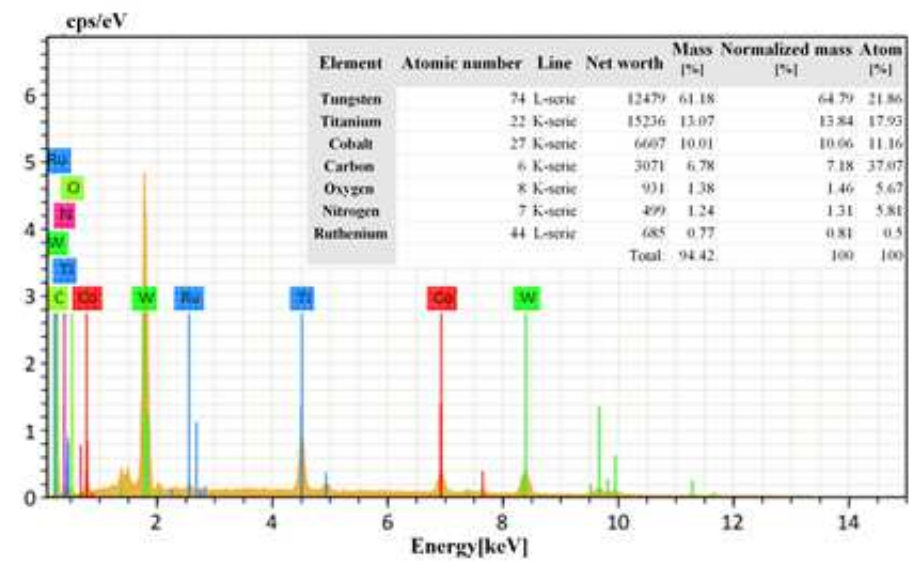

(d) Energy spectrum analysis of Zone C 
Tool wear morphology of the self-propelled rotary milling cutter at a milling length of $210 \mathrm{~m}$

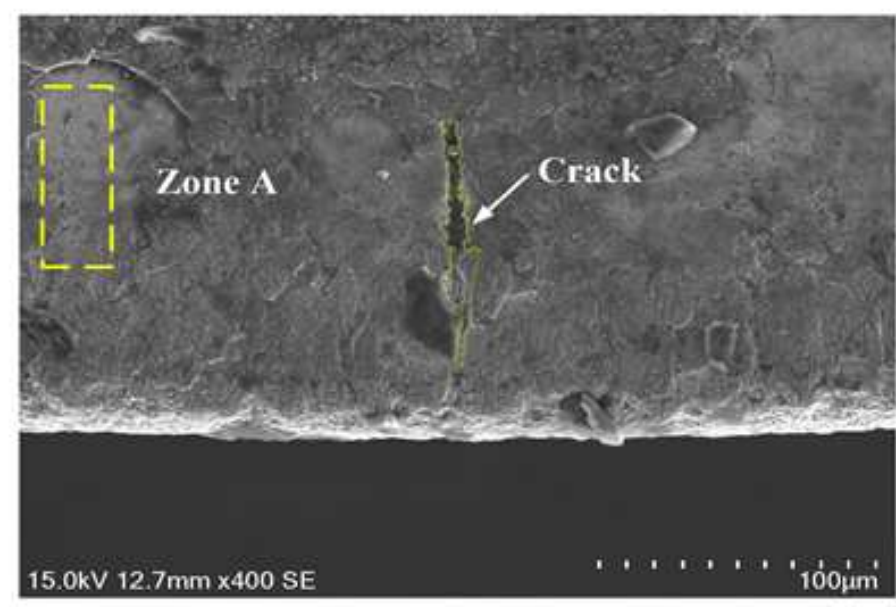

(a) Crack morphology on the cutter surface

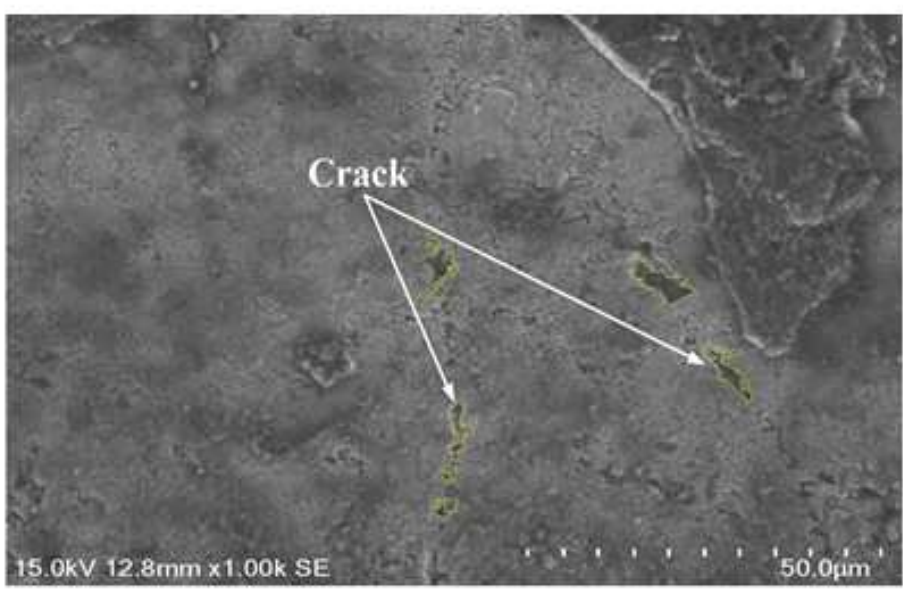

(b) Magnified crack morphology in Zone A

\section{Figure 8}

Tool wear morphology of the self-propelled rotary milling cutter at a milling length of $330 \mathrm{~m}$
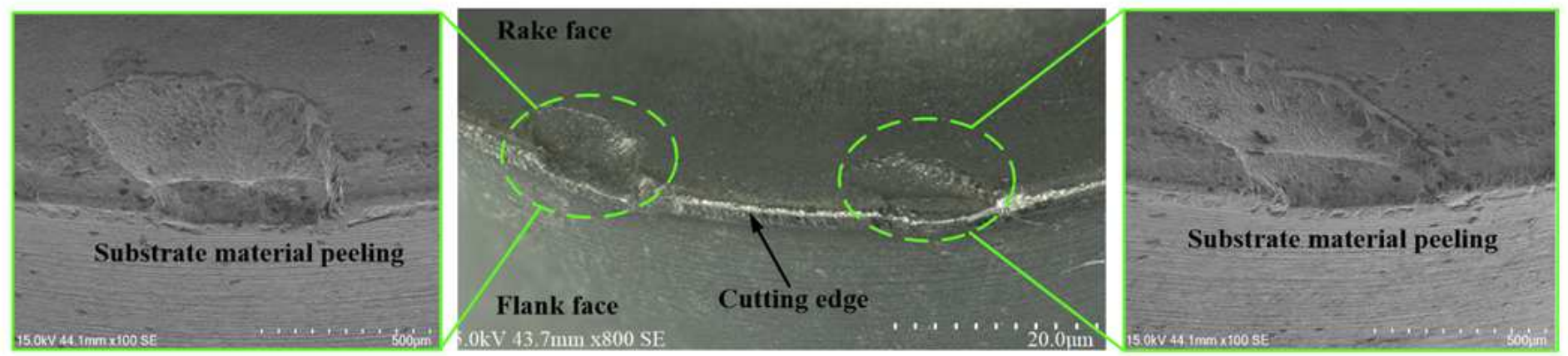

\section{Figure 9}

Tool wear morphology of the self-propelled rotary milling cutter at a milling length of $411 \mathrm{~m}$ 


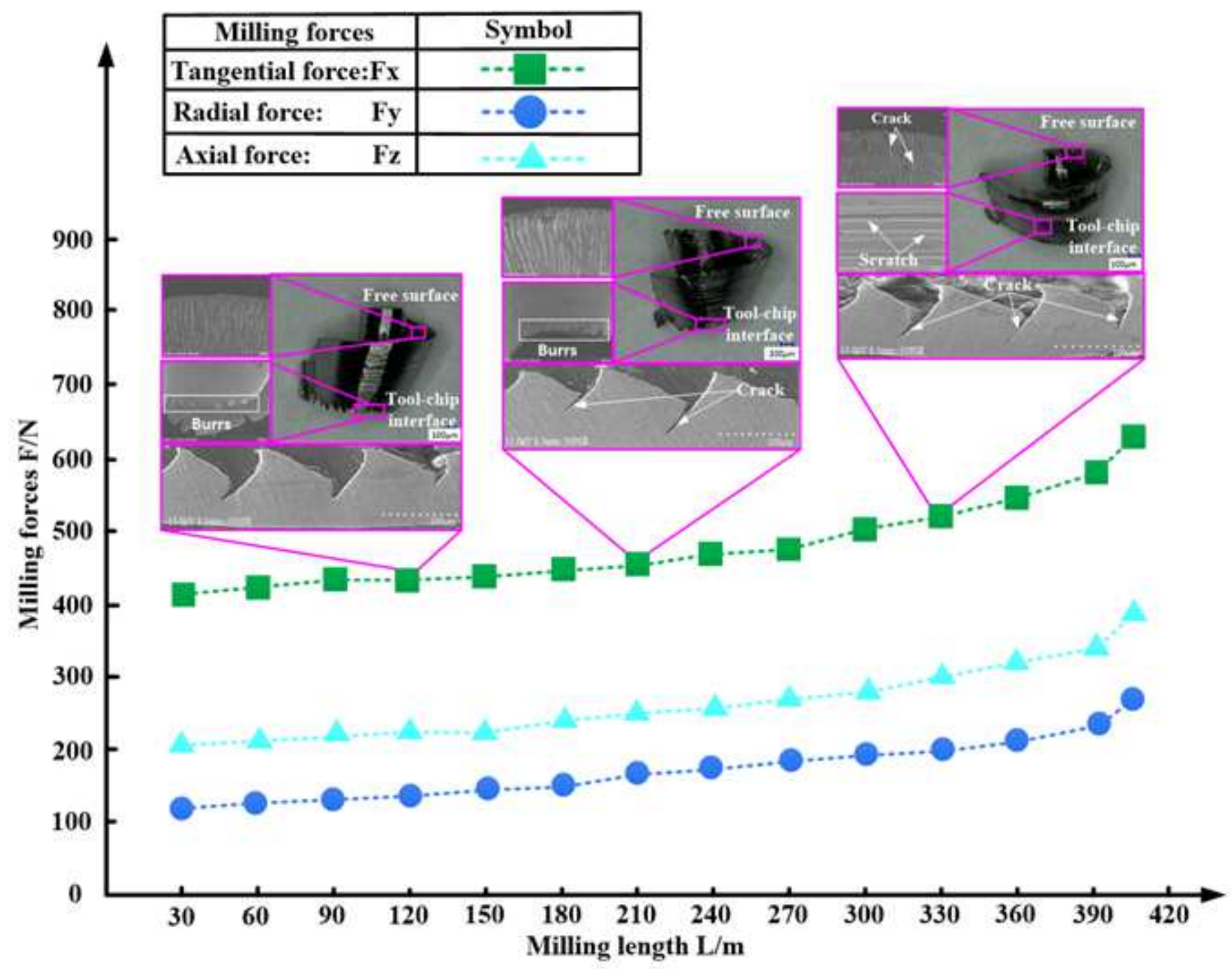

Figure 10

Variation of milling forces and chip morphology at different milling lengths 


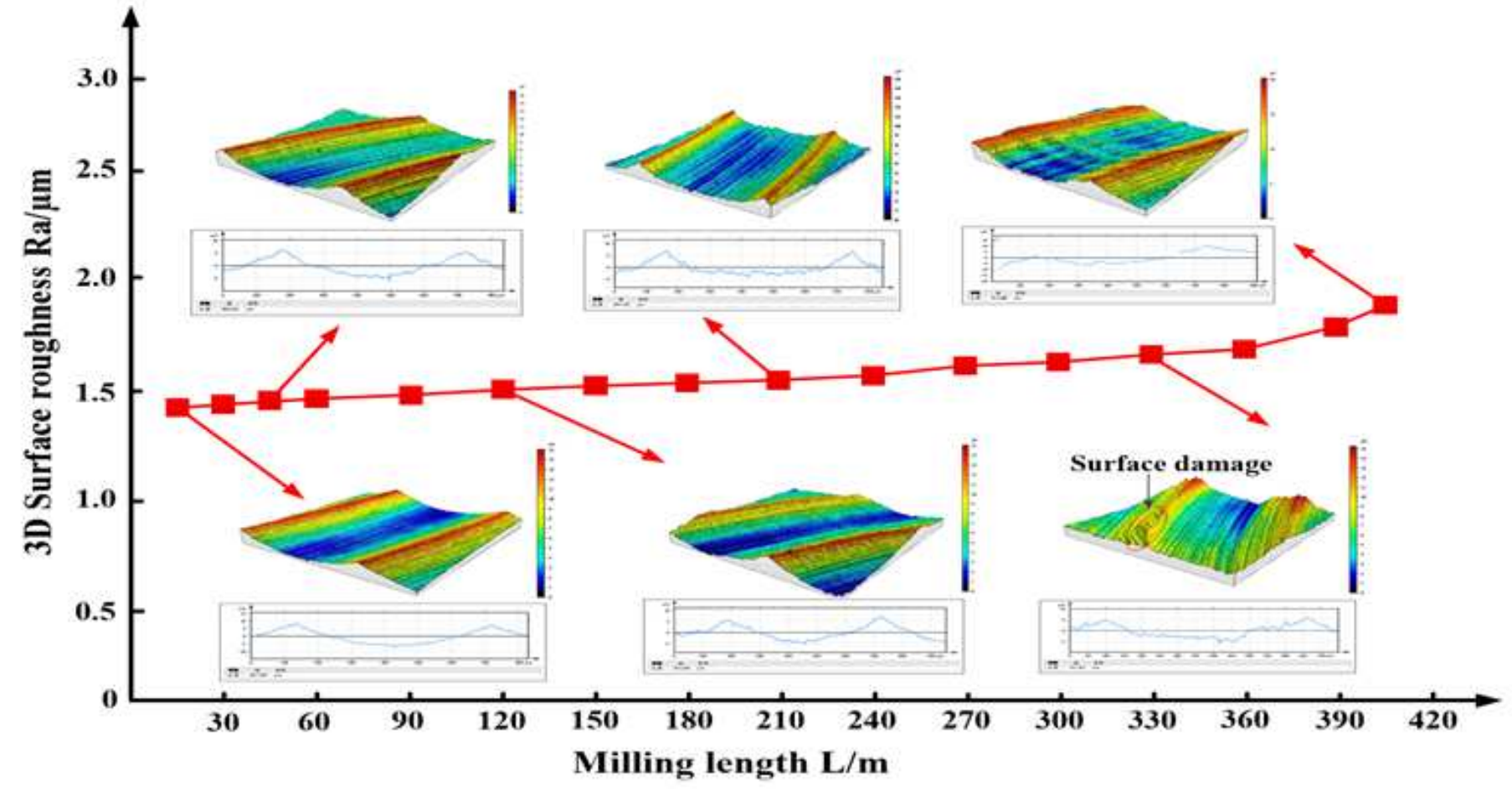

Figure 11

Varying curves of the machined surface roughness with the milling length

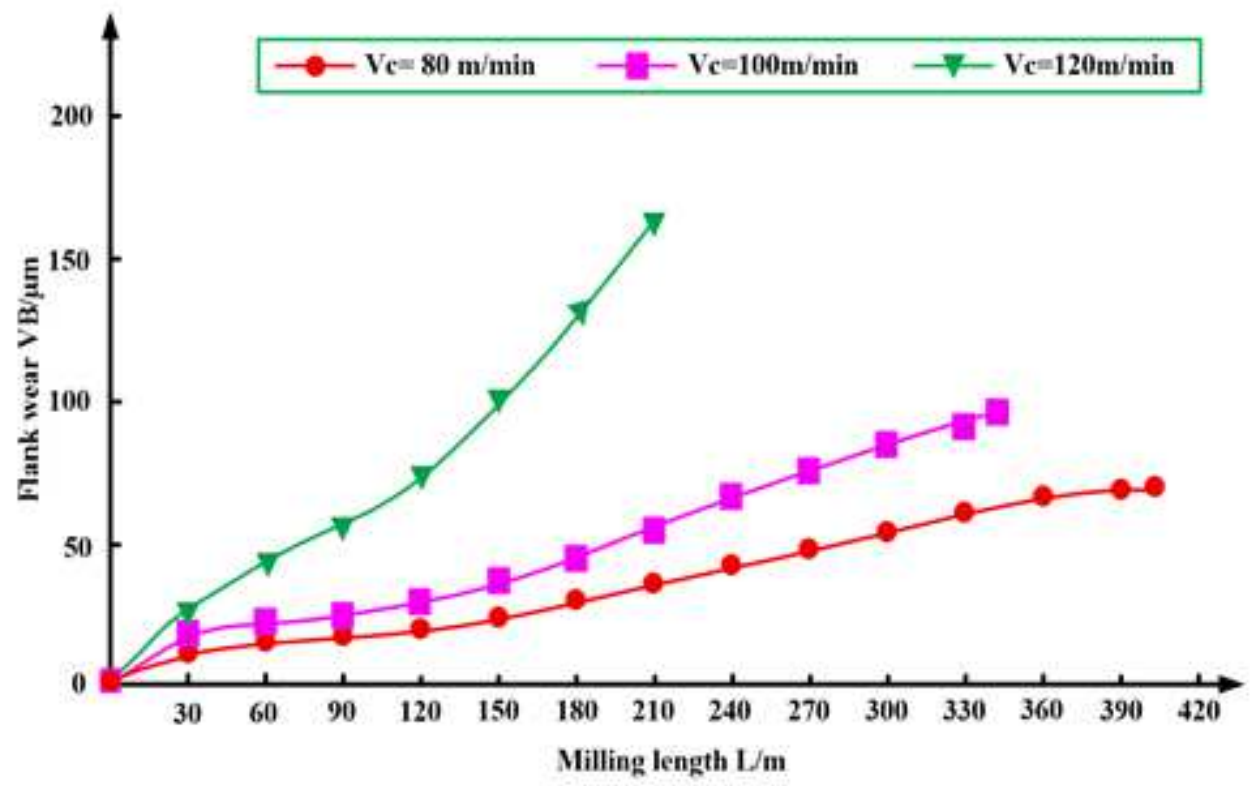

Figure 12

Tool wear curves of the SPRMC at different milling velocities 


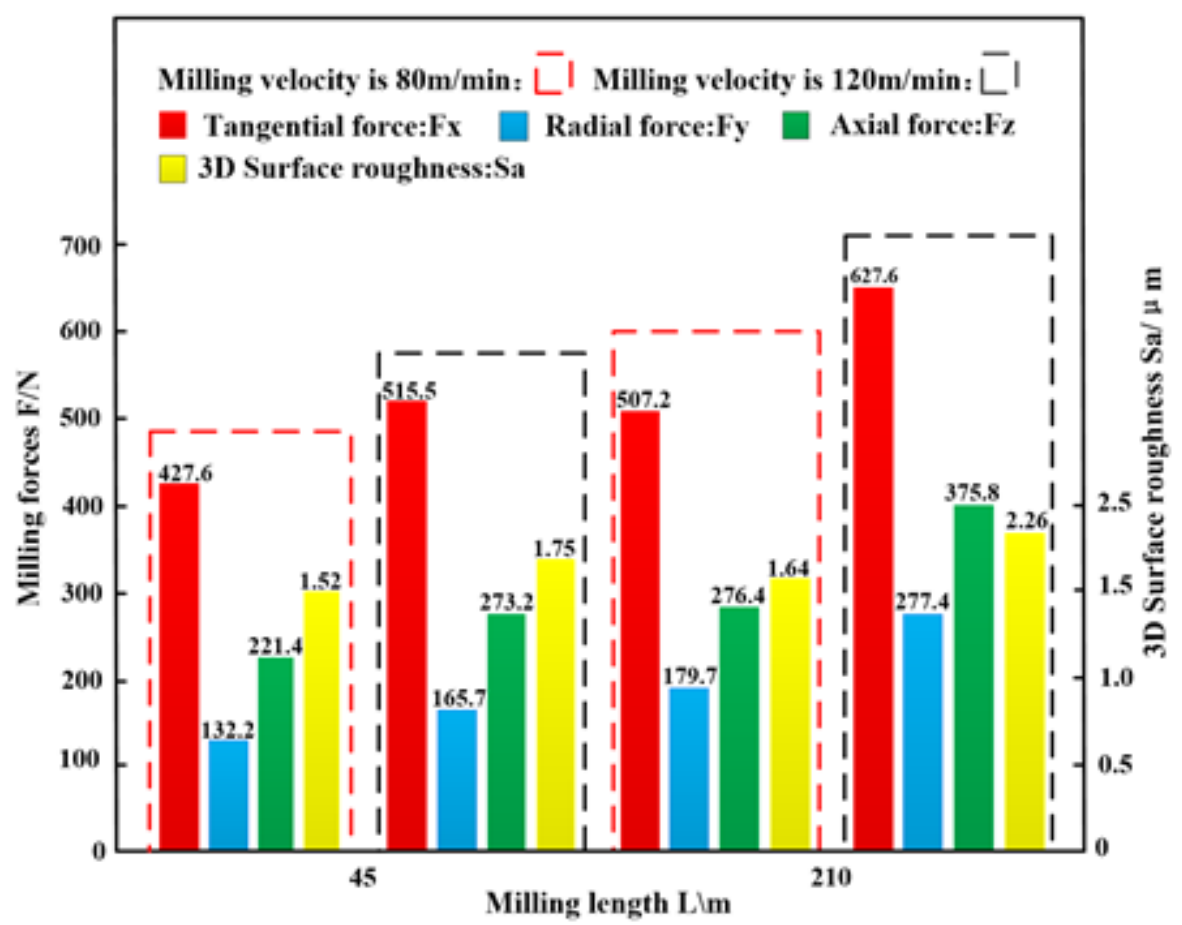

Figure 13

Comparison of the milling forces and surface roughness at different milling lengths

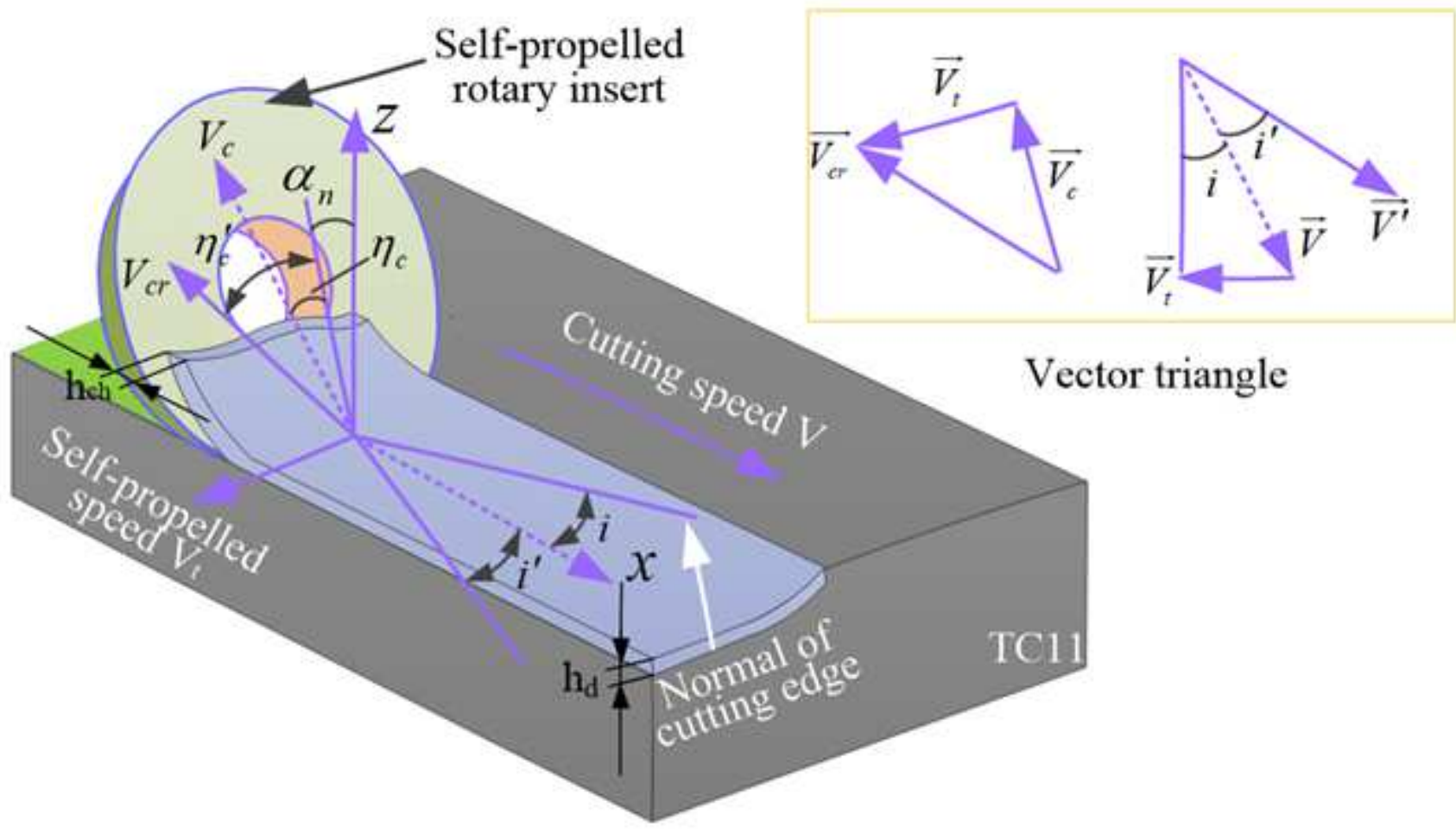

Figure 14 
The state of high-speed milling of TC11titanium alloy with the SPRMC

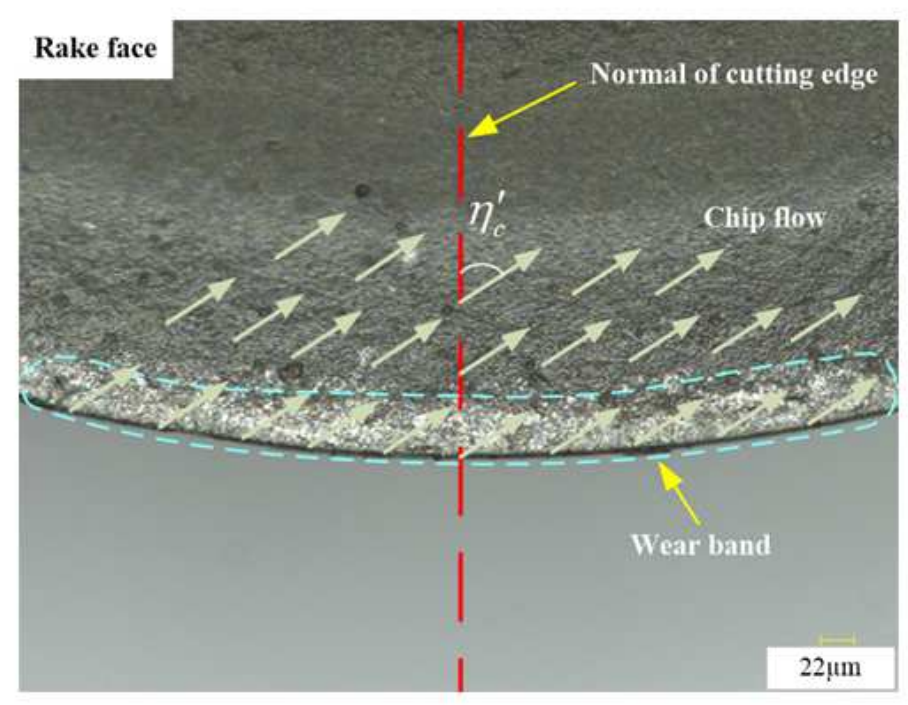

(a) $80 \mathrm{~m} / \mathrm{min}$

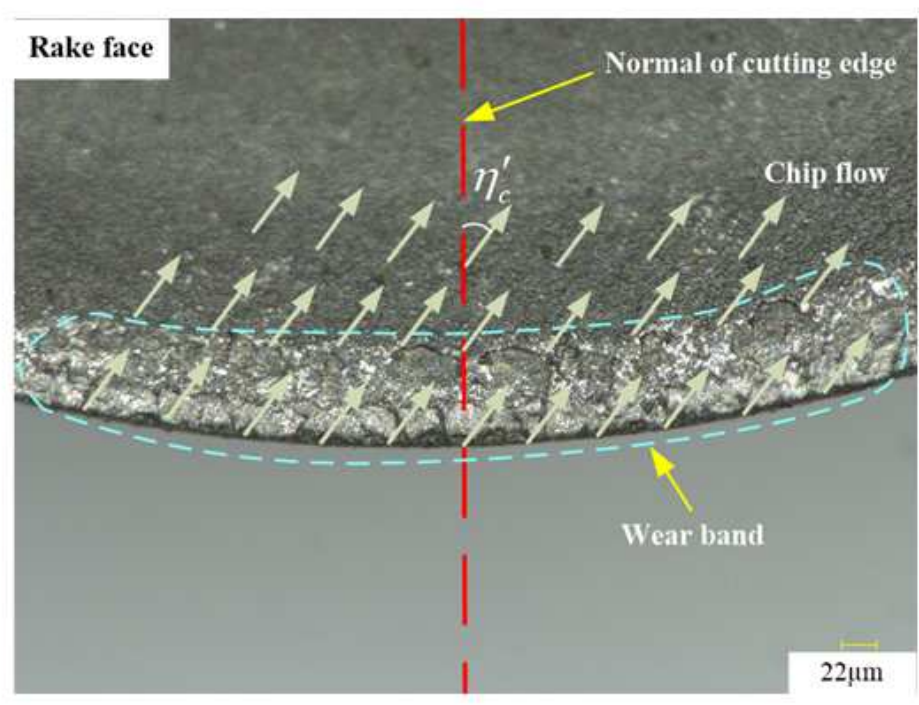

(b) $120 \mathrm{~m} / \mathrm{min}$

\section{Figure 15}

Rake wear morphology at a milling length of $45 \mathrm{~m}$ at different milling velocities 